NBER WORKING PAPER SERIES

\title{
DURATION DEPENDENCE AND LABOR MARKET CONDITIONS: THEORY AND EVIDENCE FROM A FIELD EXPERIMENT
}

\author{
Kory Kroft \\ Fabian Lange \\ Matthew J. Notowidigdo \\ Working Paper 18387 \\ http://www.nber.org/papers/w18387
}

\author{
NATIONAL BUREAU OF ECONOMIC RESEARCH \\ 1050 Massachusetts Avenue \\ Cambridge, MA 02138 \\ September 2012
}

\begin{abstract}
We thank Marianne Bertrand, Eric Budish, Jon Guryan, Yosh Halberstam, Rob McMillan, Phil Oreopoulos, Paul Oyer, Yuanyan Wan, and seminar participants at University of Rochester, McGill University, Utah Winter Business Economics Conference, University of North Carolina, Duke University, Iowa University, McMaster University, George Mason University, and Oberlin College for helpful comments. We thank Thomas Bramlage, Rolando Capote, David Hampton, Mark He, Paul Ho, Angela Li, Eric Mackay, Aaron Meyer, Nabeel Thomas, Stephanie Wu, Steven Wu, Vicki Yang, and Dan Zangri for excellent research assistance. We thank Ben Smith for excellent research assistance and exceptional project management throughout the experiment, and we thank Bradley Crocker at HostedNumbers.com for assistance with setting up the local phone numbers used in the experiment. We gratefully acknowledge the Initiative on Global Markets at the University of Chicago Booth School of Business, the Neubauer Family Assistant Professorship, and the Connaught Fund for financial support. The views expressed herein are those of the authors and do not necessarily reflect the views of the National Bureau of Economic Research.
\end{abstract}

NBER working papers are circulated for discussion and comment purposes. They have not been peerreviewed or been subject to the review by the NBER Board of Directors that accompanies official NBER publications.

(C) 2012 by Kory Kroft, Fabian Lange, and Matthew J. Notowidigdo. All rights reserved. Short sections of text, not to exceed two paragraphs, may be quoted without explicit permission provided that full credit, including ( $)$ notice, is given to the source. 
Duration Dependence and Labor Market Conditions: Theory and Evidence from a Field Experiment Kory Kroft, Fabian Lange, and Matthew J. Notowidigdo

NBER Working Paper No. 18387

September 2012

JEL No. J64

\begin{abstract}
$\underline{\text { ABSTRACT }}$
This paper studies the role of employer behavior in generating "negative duration dependence" -- the adverse effect of a longer unemployment spell -- by sending fictitious resumes to real job postings in 100 U.S. cities. Our results indicate that the likelihood of receiving a callback for an interview significantly decreases with the length of a worker's unemployment spell, with the majority of this decline occurring during the first eight months. We explore how this effect varies with local labor market conditions, and find that duration dependence is stronger when the labor market is tighter. We develop a theoretical framework that shows how the sign of this interaction effect can be used to discern among leading models of duration dependence based on employer screening, employer ranking, and human capital depreciation. Our results suggest that employer screening plays an important role in generating duration dependence; employers use the unemployment spell length as a signal of unobserved productivity and recognize that this signal is less informative in weak labor markets.
\end{abstract}

Kory Kroft

Department of Economics and

School of Public Policy and Governance

University of Toronto

150 St. George Street

Toronto, ON M5S 3G7

kory.kroft@utoronto.ca

Fabian Lange

McGill University

Department of Economics

855 Sherbrooke Street West

Montreal, Quebec, H3A 2T7

fabolange@gmail.com

\author{
Matthew J. Notowidigdo \\ University of Chicago \\ Booth School of Business \\ 5807 South Woodlawn Avenue \\ Chicago, IL 60637 \\ and NBER \\ noto@chicagobooth.edu
}




\section{Introduction}

Does the length of time out of work diminish a worker's job market opportunities? This question attracts substantial attention from policymakers and researchers alike, reflecting the widespread belief that the adverse effect of a longer unemployment spell - what economists call "negative duration dependence" - undermines the functioning of the labor market and entails large social costs. Recently, the sharp rise in long-term unemployment has renewed interest in duration dependence; according to a recent report by the Congressional Budget Office, long-term unemployment may "produce a self-perpetuating cycle wherein protracted spells of unemployment heighten employers' reluctance to hire those individuals, which in turn leads to even longer spells of joblessness" (CBO 2012).

Despite this widespread interest, it has proven very difficult to credibly establish that a longer unemployment spell has a genuine causal effect on an individual's job-finding probability. The difficulty arises because workers with different unemployment spell lengths who appear (otherwise) similar to researchers may actually look very different to employers. As a result, in observational data, job-finding rates might decline with unemployment duration either because of "true" duration dependence or because unemployment spell lengths correlate with other fixed characteristics that are observed by employers, but not researchers. ${ }^{2}$ Perhaps as a result of this challenge, empirical evidence on duration dependence is mixed. Van den Berg and van Ours (1996) find that, "except for white men, duration dependence is dominated by unobserved heterogeneity." Machin and Manning (1998) review the large literature and find little evidence of duration dependence, once one controls for observable fixed characteristics. On the other hand, studies by Imbens and Lynch (2006) and Shimer (2008) find evidence of negative duration dependence. The state of the empirical literature is succinctly summarized by Ljungqvist and Sargent (1998), who write: "It is fair to say that the general evidence for duration dependence is mixed and controversial".

In this paper, we confront this challenge by estimating duration dependence using a large-scale resume audit study. We submit fictitious resumes to real, online job postings in each of the 100 largest metropolitan areas (MSAs) in the U.S., and we track "callbacks" from employers for each submission. In total, we apply to roughly 3,000 job postings in Sales, Customer Service, Administrative Support, and Clerical job categories, and we submit roughly 12,000 resumes. In designing each resume, we explicitly randomize both the employment status and the length of the current unemployment spell from 1 to 36 months (if the worker is unemployed), so that the unemployment spell length is orthogonal to all of the other characteristics of the resume that are observable by potential employers. ${ }^{3}$ Our experiment therefore directly uncovers duration

\footnotetext{
${ }^{2}$ More broadly, this challenge relates to the standard econometric problem of distinguishing state dependence from unobserved heterogeneity. Previous work has shown that without functional form assumptions on job-finding rates, it is not possible to distinguish between duration dependence and unobserved heterogeneity using observational data with a single unemployment spell for each individual (Heckman and Singer 1984). Multiple-spell data can resolve this identification problem, but at the cost of strong assumptions on how job-finding rates vary across unemployment spells for a given individual.

${ }^{3}$ To be precise, from the employer's perspective, a "gap" in work experience on a CV technically corresponds to a period of non-employment. Nevertheless, we will refer to this gap throughout as an unemployment spell, although we recognize that this
} 
dependence arising through employers' beliefs about unemployed workers.

To help guide our empirical analysis and interpret our experimental results, we develop a simple "mechanical model" of unemployment. We label the model "mechanical" since it does not contain any microfoundations for firm or worker behavior. Firms are homogeneous and workers can be of two types: high or low. Workers are born continuously into unemployment and meet firms randomly. We characterize the jobfinding probability for an unemployed worker (at a given unemployment duration) under three assumptions. First, firms are more likely to hire high type workers ("Assumption 1"). Second, for both types of workers, the chance of getting hired increases with the share of high types ("Assumption 2"). Third, worker type and the share of high types are both weakly separable from market tightness in the job-finding rate ("Assumption 3"). We show formally that Assumptions 1-2 imply negative duration dependence in job-finding rates, and Assumptions 1-3 imply that duration dependence is stronger when the labor market is tighter (i.e., a higher ratio of vacancies to unemployed workers).

There are two key advantages of pursuing this reduced-form modeling approach. First, it allows us to isolate in a clear way the assumptions that are pivotal in generating negative duration dependence (Assumptions 1 - 2). Second, it is useful in discerning among leading models of duration dependence (Assumptions 1 - 3). We show that employer screening models (Vishwanath 1989; Lockwood 1991) satisfy Assumptions 1-3 and therefore predict negative duration dependence and a positive relationship between duration dependence and market tightness. On the other hand, we show that alternative models of duration dependence do not satisfy all three assumptions and therefore differ in their predictions regarding how duration dependence varies across local labor markets. The employer ranking model (Blanchard and Diamond 1994; Moscarini 1997) predicts a negative interaction between duration dependence and market tightness, and a model of human capital depreciation (Acemoglu 1995) predicts no interaction since the rate of human capital depreciation does not vary with market tightness. Thus, it is possible to distinguish between leading models of duration dependence by examining how duration dependence varies with labor market conditions. Our second major empirical contribution is to implement this test empirically. To do this, we exploit variation in labor market tightness across 100 local labor markets.

Turning to empirical results, a simple plot of the raw data displays clear visual evidence of negative duration dependence: the average callback rate sharply declines during the first eight months of unemployment and then it stabilizes. OLS regression results confirm the pattern from the nonparametric plot. At eight months of unemployment, callbacks are about 45 percent lower than at one month of unemployment, as the callback rate falls from roughly $7 \%$ to $4 \%$ over this range. After eight months of unemployment, we find that the marginal effect of additional months of unemployment is negligible. To benchmark the

is not the conventional definition. Our view is that the current gap represents the best available information to an employer about a job seeker's current job market status; in particular, whether he or she is currently unemployed, and what that signals about his/her productivity. 
magnitude of this result, in their study of racial discrimination, Bertrand and Mullainathan (2004) find that Black-sounding names received about 33 percent fewer callbacks than White-sounding names. The sharp drop in the callback rate at the beginning of the spell suggests that gradual loss of skill is unlikely to be the sole factor that accounts for duration dependence.

We next estimate how duration dependence varies with labor market conditions. Our results indicate that duration dependence is significantly stronger when the local labor market is tight. This finding is robust to using several different measures of market tightness: first, the callback rate for a newly-unemployed individual in each MSA, a measure which is motivated by the mechanical model; second, metropolitan area monthly unemployment rates; finally, metropolitan area-level data on vacancies and unemployment (from the Help Wanted OnLine Index and the BLS, respectively). As the model makes clear, these results are consistent with employers using unemployment spell length as a signal of unobserved productivity, and employers recognizing that this signal is less informative in weak labor markets. However, we emphasize that our evidence does not rule out a role for human capital depreciation, as well. For instance, it is possible that both human capital depreciation and screening are operative in generating negative duration dependence across all local labor markets, with the screening component leading to an interaction effect with market tightness.

Most closely related to our work is Oberholzer-Gee (2008) and Eriksson and Rooth (2011), who also investigate how employers respond to unemployment spells using a resume audit study. Oberholzer-Gee (2008) analyzes Swiss employer responses to 628 resume submissions. Eriksson and Rooth (2011) submit 8,466 job applications to 3,786 employers in Sweden and compare the effects of contemporary and past unemployment spells (e.g., unemployment spells at graduation). Both of these studies report results consistent with the long-term unemployed being less likely to receive callbacks. Our study builds on these papers in two ways: first, unlike these studies which randomize across a small number of unemployment spell lengths, our study estimates a callback rate for each month in the interval $[1,36]$. This allows us to flexibly estimate the relationship between callback rate and unemployment duration, which we find is highly nonlinear. Second, neither of these papers considers how duration dependence varies across local labor markets, a key feature of our experiment.

To address the concern (both in our work and in the related papers above) that the unemployment spell length is not salient to employers, we administer a web-based survey to MBA students. Our survey results indicate that the length of the current unemployment spell is salient to the survey participants; in particular, subjects were able to recall a worker's employment status and unemployment spell length with roughly the same degree of accuracy and precision as other resume characteristics such as education and job experience. This supports our assumption that the way we represent unemployment durations on resumes is salient to the employers in our experiment. 
The remainder of the paper proceeds as follows: Section 2 develops the mechanical model. Section 3 describes the main predictions from three specific models of duration dependence: the employer screening model, the human capital depreciation model, and the employer ranking model. Section 4 describes the experimental design, the resuls from the web-based survey, and the empirical models. Section 5 describes our experimental results. Section 6 concludes.

\section{Mechanical Model}

This section describes a mechanical model of unemployment. We purposely label the model "mechanical" since it is not explicitly based on microfoundations; it does not specify an information structure, firm or worker objectives, or a wage setting process. The question we address is the following: What properties on the job-finding process lead to duration dependence and how does duration dependence vary with labor market conditions? By considering a reduced-form approach to this problem, we simplify the analysis considerably. More importantly, this approach demonstrates that the predictions of the model are general: we show in Section 3 that a class of employer screening models, including a generalized version of the screening model in Lockwood (1991), map into the reduced-form of this mechanical model and therefore generate the same comparative statics. Thus, the approach pursued here can be thought of as identifying the pivotal assumptions in screening models that feature duration dependence in unemployment.

\subsection{Population Flows}

We consider economies in steady state such that inflows into unemployment are equal to outflows out of unemployment. A population of mass 1 is born continuously into unemployment. There are two possible types: either "high" $(y=h)$ or "low" $(y=l)$. The fraction of these two types are $\pi_{0}$ and $1-\pi_{0}$, respectively. In the screening model below, worker type will correspond to unobserved worker productivity.

In the unemployed population, we allow the share of high types to depend on unemployment duration, which we denote by $d$. Formally, we define:

$$
\pi(d) \equiv \operatorname{Pr}(y=h \mid d)
$$

In terms of outflows, we assume that individuals transition out of unemployment either by finding a job or by retiring. We assume that the job-finding rate depends on worker type and the share of high types, and we denote this rate by $h_{y}(\pi(d))$.

We assume that individuals retire at an exogenous rate $\delta$ which does not depend on worker type or labor market status. The decision to assume away job separations is primarily to keep the analysis simple. Employer screening models that feature job separations are more complicated since this provides another 
source of information to potential employers to learn about worker productivity. Our interest is characterizing the adverse effects of a current spell of unemployment. While characterizing the effects of a worker's entire work history is interesting, it is beyond the scope of our study. We therefore follow Lockwood (1991) and assume that a worker is employed with at most a single firm in his lifetime.

The individual exit rate out of unemployment is the sum of the individual job-finding rate and retirement rate:

$$
h_{y}(\pi(d))+\delta
$$

Given the escape rate in equation $(2), \pi(d)$ satisfies:

$$
\pi(d)=\frac{\pi_{0} \exp \left(-\int_{0}^{d}\left(h_{h}(\pi(\tau))+\delta\right) d \tau\right)}{\pi_{0} \exp \left(-\int_{0}^{d}\left(h_{h}(\pi(\tau))+\delta\right) d \tau\right)+\left(1-\pi_{0}\right) \exp \left(-\int_{0}^{d}\left(h_{l}(\pi(\tau))+\delta\right) d \tau\right)}
$$

To interpret equation (3), recall that the unemployed population at $d=0$ is normalized to 1 , so $\pi_{0}$ gives the number of newly unemployed high types and the term $\exp \left(-\int_{0}^{d}\left(h_{h}(\pi(\tau))+\delta\right) d \tau\right)$ is the survival function for high types. Thus, the numerator exactly represents the number of high types that are unemployed after $d$ periods. By similar logic, the denominator is the total number of individuals that are unemployed at duration $d$. Thus, their ratio pins down $\pi(d)$.

Finally, given the individual job-finding rate and the share of high types, we can define the population job-finding rate at a given duration as a mixture of the type-specific job-finding rates:

$$
h(\pi(d))=\pi(d) h_{h}(\pi(d))+(1-\pi(d)) h_{l}(\pi(d))
$$

Expression (4) shows that the population job-finding rate varies with unemployment duration through two channels. First, it varies directly with duration through the share of high type workers. This source of variation represents "unobserved heterogeneity". Intuitively, the composition of types at risk of leaving unemployment shifts over time. Second, it varies indirectly with duration through the individual job finding rates. This source of variation captures "true duration dependence" and represents how the population jobfinding rate varies over the spell, holding the share of high types constant. Ultimately, both sources depend on how the share of high types varies over the unemployment spell, so that the two sources of duration dependence interact and reinforce each other.

\subsection{Duration Dependence}

To operationalize the model, we impose two key assumptions on the individual job-finding rate. The first assumption states that there is heterogeneity in job-finding rates across types, so that one type finds jobs at higher rates than the other. Without loss of generality, we assume that the "high" type finds job at a higher 
rate.

Assumption 1 At a given unemployment duration, high types find jobs at higher rates than low types:

$$
h_{h}(\pi(d))>h_{l}(\pi(d))
$$

The second assumption restricts how the type-specific job-finding rates vary with the share of high types in the unemployed population.

Assumption 2 The individual job-finding rates increase in the share of high types:

$$
\frac{\partial h_{y}(\pi(d))}{\partial \pi} \geq 0
$$

Assumptions 1 and 2 are intuitively explained in the context of employer screening models (Vishwanath 1989; Lockwood 1991). In such models, worker types differ in productivity, firms draw signals on worker productivity, and firms set a hiring threshold for signals. Since the signals are informative on worker productivity, high types are more likely to draw high signals and be hired. Assumption 2 is satisfied since the hiring threshold decreases in the firm's prior that a worker is productive. Under rational expectations, this threshold equals the share of high types in the unemployed population.

The next proposition states that the proportion of high types among the unemployed and, as a result, the job-finding rates decline with duration.

Proposition 1 The proportion of high types in the unemployed population (3) and the population job-finding rate (4) decline strictly with duration. The individual job-finding rate declines weakly with duration d. Thus, the model features negative duration dependence in unemployment.

The proof is straightforward. First, by Assumption 1, high types find jobs more frequently than low types. As a result, the composition of the unemployed shifts to low types at longer durations. Since the share of high types declines over the spell and since individual job-finding rates are increasing in the share of high types (Assumption 2), individual job-finding rates decline over the spell. Finally, the population job-finding rate declines due to true negative duration dependence and unobserved heterogeneity. ${ }^{4}$

To study how duration dependence interacts with market tightness, we impose more structure on individual job-finding rates. First, we assume that a single worker and a single firm randomly meet according to the constant returns to scale (CRS) matching function $m(U, V)$, where $U$ and $V$ are the number of unemployed

\footnotetext{
${ }^{4}$ More formally, define $\theta(d)=\frac{\pi(d)}{1-\pi(d)}$. Differentiating $\theta(d)$ with respect to $d$ and applying Assumption 1 gives $\pi^{\prime}(d)<0$. This combined with Assumption 2 delivers $\frac{\partial h_{y}(\pi(d))}{\partial d} \leq 0 . \quad$ Finally, $\frac{\partial h(\pi(d))}{\partial d}=(1-\pi(d)) \frac{\partial h_{l}(\pi(d))}{\partial d}+\pi(d) \frac{\partial h_{h}(\pi(d))}{\partial d}+\underset{\leq 0}{\leq 0}$ $\underset{<0}{\frac{\partial \pi(d)}{\partial d}}\left(h_{h}(\pi(d)) \underset{>0}{<} h_{l}(\pi(d))\right)<0$
} 
workers and vacancies, respectively. Defining $x=\frac{V}{U}$ as labor market tightness, the CRS assumption implies that the rate at which unemployed individuals are matched with vacancies depends only on labor market tightness. Under this assumption, worker type does not influence the arrival rate of jobs offers. This is useful since it allows us to isolate the consequences of employer behavior.

Once a firm and worker have matched, we assume that the conditional hiring rate depends on worker type and the share of high types in the population. We denote this rate by $l_{y}(\pi(d ; x))$ and assume that $l_{h}(\pi)>$ $l_{l}(\pi)$ and $\frac{\partial l_{y}(\pi)}{\partial \pi} \geq 0$, which ensures that the individual job-finding rate continues to satisfy Assumptions 1 and 2. The third key assumption of the model governs how individual job-finding rates vary with market tightness.

Assumption 3 In the individual job-finding rate, the type of the worker and the share of high types conditional on duration are weakly separable from market tightness:

$$
h_{y}(d ; x)=m(x) \times l_{y}(\pi(d ; x))
$$

We next define the following function:

$$
r(d ; x)=\frac{h(d ; x)}{h(0 ; x)}
$$

The function $r(d ; x)$ is the ratio of the population job-finding rate evaluated at duration $d$ to the population job-finding rate among the newly unemployed. This is an intuitive measure of the strength of duration dependence. If there is negative duration dependence, this ratio is below 1; conversely, if there is positive duration dependence, this ratio exceeds $1 .^{5}$ A key property of this ratio is that it depends on market tightness only through the share of high types. The effect of market tightness on duration dependence occuring through the arrival rate is not operational since it affects the job-finding rate at all durations in a uniform way. This leads to the second proposition.

Proposition 2 Duration dependence is stronger (more negative) when labor markets are tighter.

Formally, this proposition states that $r(d ; x)$ for tight labor markets (large $x)$ lies everywhere below the function $r(d ; x)$ observed in loose labor markets (small $x)$; i.e., $\partial r(d ; x) / \partial x<0$. For a mathematical proof, we refer the reader to Appendix A. Intuitively, in tight labor markets, workers are more likely to meet early on with firms. By Assumption 3, this rate of matching does not depend on worker type. Assumption 1 guarantees that high types are relatively more likely to exit unemployment when matched with a firm.

\footnotetext{
${ }^{5}$ An alternative measure of how duration dependence varies with market tightness is the cross-derivative of this function: $\frac{\partial^{2} r(d ; x)}{\partial d \partial x}$. However, the cross-derivative is local, and it can be positive for some values of $d$ and negative for others. As it turns out, our measure has no general implications for such local measures of duration dependence. Instead, we will use a global measure that holds for all positive values of $d$.
} 
This selection effect implies that the share of low types is relatively larger among the long-term unemployed. By Assumption 2, this strengthens duration dependence. By contrast, in loose labor markets, both worker types are less likely to meet open vacancies. Therefore, the share of high types will vary little over time, generating less duration dependence. As described in more detail in Appendix C, in employer screening models that are consistent with this mechanical model, market tightness affects the job-finding rate through two channels. First, it affects the rate at which workers meet firms. Second, it controls the precision of the information revealed by a worker's unemployment duration. In tight markets, a long unemployment spell reveals that the worker has likely been previously found unsuitable by prospective employers. Thus, the conditional hiring rate will implicitly depend on market tightness.

\subsection{Callbacks}

Propositions 1 and 2 deliver testable predictions on job-finding rates. However, in our audit experiment, we do not observe hiring decisions, but rather whether applicants are called back for interviews. To align the theory more closely with our empirical application, we now adapt the model to incorporate an interview stage and callbacks. We define the callback rate as the probability that a worker gets invited for an interview. This is to be distinguished from the job-finding rate, the (joint) probability a worker receives a callback and gets hired.

The decision to interview a worker will depend on individual characteristics in addition to the duration of unemployment. We represent these characteristics by the vector $\phi$ and denote its distribution conditional on type $y$ and duration $d$ by $\Phi_{y}(. \mid d)$. The unconditional distribution is given by $\Phi(. \mid d) .{ }^{6}$ We denote the share of high types in the population by $\pi(d ; \phi)$.

We consider the case where the callback rate has the form $c(\pi(d ; \phi) ; x)$ and we assume that it is weakly increasing in the high type share. When $d=0$, the callback rate varies with market tightness only through the congestion channel; in particular, the information channel is absent. Intuitively, a newly unemployed worker reveals no information to firms that can be used to predict productivity. Thus, in our empirical work, we will use the callback rate of a newly unemployed worker as a measure of market tightness. The population job-finding rate, conditional on $\phi$, is obtained by replacing $\pi(d)$ with $\pi(d ; \phi)$ and $h_{y}(\pi(d))$ with $h_{y}(\pi(d ; \phi))$ in equation (4). This immediately implies the following corollary to Proposition 1:

\section{Corollary 1 Callback rates exhibit negative duration dependence.}

Intuitively, once all of a worker's characteristics $(\phi)$ are accounted for, back luck that leads to a longer duration at the individual level will lead to a callback rate that declines at the individual level. Next, as an

\footnotetext{
${ }^{6} \Phi(. \mid d)$ is equal to $\pi(d) \Phi_{h}(. \mid d)+(1-\pi(d)) \Phi_{l}(. \mid d)$.
} 
analog to the function $r(d ; x)$, we define the relative ratio of callback rates:

$$
r_{c}(d ; x, \phi)=\frac{c(d ; \phi ; x)}{c(0 ; \phi ; x)}
$$

This delivers the following corollary to Proposition 2:

Corollary 2 Duration dependence in the callback rate is stronger if markets are tighter.

Formally, this corollary states that conditional on $\phi, r_{c}(d ; x, \phi) \geq r_{c}\left(d ; x^{\prime}, \phi\right)$ if $x<x^{\prime}$. The practical value of this corollary is that it implies we can use callback rates to test the implications on job-finding rates that we derived above. In practice, it is difficult to empirically test for true duration dependence in callback rates using observational data. If an econometrician cannot fully account for the impact of $\phi$ on callbacks, the estimate of $\frac{\partial c(\pi(d ; \phi))}{\partial d}$ will be confounded by composition bias. For example, it is easy to account for some characteristics on a resume (such as gender, education and experience). However, resumes are complex and it is difficult to fully control for all characteristics. Even though the econometrician might have access to the entire resume, he will not know the complete mapping between callbacks and all of the variables on the resume and potential interactions between them.

To illustrate this bias more formally, consider the extreme case where callbacks depend only on $\phi$, so that we may write the callback rate as $c(\phi)$. Furthermore, assume that $c^{\prime}(\phi)>0$. This represents a situation where firms do not condition their callback decisions on $d$; there is no true duration dependence under this formulation. Assume that $\phi$ is unobserved by the econometrician. The population callback rate $c(d)$ is defined as follows:

$$
c(d) \equiv \int c(\phi) \frac{d \Phi(\phi \mid d)}{d \phi} d \phi
$$

In Appendix A, we establish that $c^{\prime}(d)<0$. Intuitively, the unemployment distribution shifts to those with low $\phi$ as spell lengths increase; resumes with long current spells of unemployment are more likely to be low $\phi$ and thus likely to have lower callback rates, even in the absence of duration dependence. Thus, in the absence of any duration dependence, callback rates will decline unless we are able to control for all relevant components of the CV.

In our resume audit study, randomization of unemployment durations ensures that the distribution of unobserved characteristics $\phi$ is independent of the duration of unemployment, and so the composition bias described above will be absent. Since we randomize unemployment duration, our experiment recovers how the average callback rate evolves with unemployment duration. More formally, define the distribution $\widetilde{\Phi}($.) as the distribution of characteristics on our experimental set of CVs. Note that this distribution will not be 
the population distribution. Instead, we recover the following object:

$$
\widetilde{c}(d)=E_{\widetilde{\Phi}}[c(\pi(d ; \phi)) \mid d]=\int_{\phi} c(\pi(d ; \phi)) d \widetilde{\Phi}(\phi)
$$

The function $\widetilde{c}(d)$ is an average over the callback rates for which the above corollary holds and the predictions of this corollary therefore also apply to $\widetilde{c}(d)$. This implies that we can use the callback rates elicited in our experiment to test the implications of the model. Finally, it is worth noting that even conditional on $\phi$, the population job-finding rate, $h(\pi(d ; \phi))$, will nevertheless decline in $d$ due in part to unobserved heterogeneity. This occurs since $h_{h}(\pi(d ; \phi))>h_{l}(\pi(d ; \phi))$ and because the share of high types conditional on $\phi$ increases with duration $d$. To see the intuition for this, consider a firm who interviews a high type and a low type worker, both of whom have the same value of $\phi$. As we show formally in the screening model in Appendix $\mathrm{C}$, it is more likely that a firm draws a relatively higher signal $(z)$ for the high type worker. Thus, workers with long durations will be those with low values of $\phi$ and low values of $z$. An econometrician who observes $\phi$ - but not the signal $z$ at the hiring stage - may be led to conclude that there is duration dependence in job-finding rates when in fact the estimates are picking up a selection effect. In this sense, it is more straightforward to identify duration dependence in callback rates than in job-finding rates, since an econometrician only needs to condition on the information that a potential employer sees at the interview stage, not the hiring stage.

\section{Employer Screening, Human Capital Depreciation, and Employer Ranking}

In this section, we briefly (and informally) present three leading behavioral models of employer-driven duration dependence. ${ }^{7}$ In doing so, we discuss whether the hiring rates in these models satisfy Assumptions 1-3 of the mechanical model in Section 2. We find that the mechanical model is not so general so as to be vacuous: there are specific behavioral models which do and do not map into the structure of the mechanical model. These models therefore do not generate the same predictions regarding the interaction between hiring rates and the strength of duration dependence.

In Appendix C, we develop a simple screening model of employer-driven duration dependence. ${ }^{8}$ Matching frictions and firm screening of workers interact to generate duration dependence in job-finding rates. Search frictions result in equilibrium unemployment: unemployed workers and vacancies meet at a rate determined

\footnotetext{
${ }^{7}$ These models are presented formally in Appendices C, D, and E.

${ }^{8}$ Our model is related to Lockwood (1991). However, we depart from Lockwood in two ways. First, we allow for an interview stage that is distinct from the hiring stage. Second, in the hiring stage, we allow for a more general signal distribution. In particular, Lockwood (1991) imposes that applicants signals are either high or low and that productive types always send the high signal, whereas unproductive types send the high signal with a probability less than one. Lockwood's model results in extreme duration dependence in the sense that upon hitting a certain duration, the probability of finding a job for a low productive type declines to zero. This extreme assumption makes it difficult to map empirical results into the framework of Lockwood (1991). By allowing for a more general, continuously distributed signal, we allow for a continuous form of duration dependence; in our model job finding rates decline smoothly with durations.
} 
by aggregate unemployment and vacancies in the economy. Upon a meeting between a vacancy and a job seeker, the potential employer obtains a signal on worker productivity. One can conceptualize this signal as the job seeker's resume. Interviewing an applicant is costly, and firms call applicants for interviews only if they receive sufficiently high signals. If a worker is called in for an interview, the firm observes an additional signal, providing new information on worker productivity. A worker with a sufficiently high signal is hired and earns his outside option. ${ }^{9}$ In this model, firms lower their priors about individuals with long durations, since they believe that these have been found wanting by other potential employers. This induces negative duration dependence.

The screening model satisfies Assumptions 1-3 of the simple mechanical model. First, high productivity workers signal their type during the interview and are hired at greater frequency than low productivity workers (Assumption 1). Second, the hiring rate increases with $\pi$ because employers' prior is $\pi$ (Assumption 2 ). Third, the matching structure implies weak separability between market tightness and $\pi$ (Assumption 3). Thus, in the screening model, duration dependence gets stronger in tight labor markets (Proposition 2). In tight markets, employers believe that the unemployed were evaluated more frequently and rejected by potential employers and firms therefore adjust their priors more. In contrast, in loose markets, it is less likely that applicants met with firms in the past. Thus, screening predicts that as labor markets tighten, duration dependence gets stronger. Therefore, the screening model can be tested by examining duration dependence in callback rates and how duration dependence interacts with market tightness.

As a contrast to the screening model, we consider two alternative models of duration dependence that do not map into the structure above. The first model, developed in Appendix D, is a model of human capital depreciation. The rate at which applicants meet firms is again governed by a matching function that depends on market tightness. Individuals' human capital affects their productivity in all firms in the same way. This human capital - common to all employers - depreciates while workers are unemployed and the rate of this depreciation does not depend on market tightness. In addition to this common human capital component, there is a worker-firm specific match component. In order to isolate the implications of human capital depreciation from screening considerations, we assume that firms are fully informed about the human capital parameter. However, firms need to interview workers in order to learn their match-specific component. As in the simple screening model, wages are given by a fixed outside option. The expected firm surplus from a given match therefore declines if an applicant has been unemployed for longer and the model generates negative duration dependence. However, the frequency with which the unemployed are matched to firms does not affect the speed with which their human capital depreciates. Therefore, this model does not generate any interaction between duration dependence and market tightness.

\footnotetext{
${ }^{9}$ The screening model can allow for less restrictive assumptions on wage setting. What is required is that applicants and firms, upon receipt of the signal, are more likely to enter into an employment relationship if the expected productivity of a worker is higher. We conjecture that most bargaining models satisfy this requirement.
} 
In Appendix E, we consider the well-known ranking model proposed by Blanchard and Diamond (1994). This model emphasizes the consequences of crowding in the labor market; vacancies potentially receive multiple applications. It is assumed that if a firm meets multiple workers, it hires the worker with the minimum duration. This assumption immediately implies that there is negative duration dependence. In addition, the ranking model has implications for how market tightness affects duration dependence. In tight markets, applicants for a given position are less likely to face competition from applicants with shorter durations. Therefore, under employer ranking, duration dependence is weaker in tight labor markets.

The key insight from our theoretical framework is that these three mechanisms for duration dependence (screening, human capital depreciation, and ranking) differ in what they predict about how duration dependence varies with local labor market conditions: screening generates a positive interaction effect, human capital depreciation does not generate an interaction effect, and ranking generates a negative interaction effect. Therefore, by estimating how duration dependence varies with labor market tightness, we will be able to shed light on the relative importance of these mechanisms. This theoretical prediction motivates a key aspect of the design of our resume audit study, which focuses on estimating duration dependence in a large number of local labor markets.

\section{Experimental Design}

The design of the field experiment follows Bertrand and Mullainathan (2004), Lahey (2008), and Oreopoulos (2011) in how we generate fictitious resumes, find job postings, and measure callback rates. All of the experimental protocols (as well as the web-based survey for MBA students) were reviewed and approved by the Institutional Review Board (IRB) at the University of Chicago. The IRB placed several constraints on the field experiment. ${ }^{10}$ First, none of the researchers involved in the study could contact the firms at any time, either during or after the experiment. Second, in order to ensure that the individual representatives of the prospective employers could never be identified, we were required to delete any e-mails or voice messages that we received from employers after ascertaining the information from the message needed for the experiment. Finally, we were not able to preserve any identifying information about the prospective employers other than the industry. By contrast, we were approved to preserve richer information on the characteristics of the job posting, such as (among other things) the posted wage and required experience.

The setting for our experiment is a single major online job board in the U.S. This online job board contains jobs advertised across most cities in the U.S., allowing us to implement our experiment in a broad set of local labor markets. Following earlier audit studies, we focus on three job categories: Administrative/Clerical, Customer Service, and Sales. Within these job categories, we sent roughly 12,000 fictitious resumes to 3,000 job openings located in the largest 100 Metropolitan Statistical Areas (MSAs) in the U.S. according

\footnotetext{
${ }^{10}$ The web-based survey instrument described below was approved with no additional constraints.
} 
to population (as measured in the 2010 Census). The distribution of the 3,000 jobs across the 100 MSAs was fixed prior to the experiment and primarily reflected the population distribution across MSAs. ${ }^{11}$ For example, we planned on submitting resumes to roughly 200 jobs to the MSA New York-Northern New Jersey-Long Island, NY-NJ-PA and roughly 15 jobs to the MSA Raleigh-Cary, NC. However, we also chose to oversample the bottom ten and top ten MSAs (within the set of 100) based on the unemployment rate in July 2011. ${ }^{12}$ Within each MSA, 30\% of jobs were allocated to Administrative/Clerical, $30 \%$ to Customer Service, and $40 \%$ to Sales.

In choosing a job to apply to, we began by randomly sampling without replacement from the distribution of MSA and job category combinations. Upon being assigned an MSA and job category, we had a Research Assistant (RA) visit the online job board and search for jobs within the pre-determined MSA for the predetermined job type. ${ }^{13}$ When picking jobs to apply to, we imposed several restrictions. First, we avoided independent outside sales positions (e.g., door-to-door sales). Second, we did not pick jobs that require advanced skill sets, licenses, or advanced degrees (beyond a standard 4-year college degree). Typically, a job opening within a given category and MSA that satisfies these criteria is immediately available, or (in rare cases) becomes available within one or two weeks.

Once a job was identified, the next step was to construct four fictitious resumes that we would customize and e-mail to this job opening. ${ }^{14}$ The design of these resumes was based on roughly 1,200 real resumes that we manually collected from various online job boards. These resumes were selected based on the job categories we focused on: individuals applying to Administrative/Clerical, Customer Service, and Sales positions. These resumes informed the design of our fictitious resumes in several ways. First, we found that workers do not "shroud" their unemployment spells: approximately $75 \%$ of resumes from workers who were currently unemployed listed both the year and month of when they last worked. Second, among the currently unemployed, roughly $95 \%$ of resumes do not provide any discernable explanation for the gap (e.g., obtained a license or certificate, engaged in community service, worked as a volunteer, training, etc); moreover, this percentage did not vary by gender or by the length of the unemployment spell. Given this, we designed all of our resumes to contain both the year and the month of last employment, and we did not purposefully try to provide any information that could be seen as accounting for the gap.

In total, we created ten resume templates that were based on the most frequent resume formats observed

\footnotetext{
${ }^{11}$ Our initial motivation for sampling based on population size was to achieve a nationally representative sample of job postings. As the experiment proceeded, however, we discovered a practical benefit of this decision, which was that we found it easier to find suitable jobs for the experiment in larger cities.

${ }^{12}$ We designed the experiment this way in order to help identify the interaction between market tightness and duration dependence. The 20 oversampled MSAs were the following: (High Unemployment MSAs) Miami, FL; Detroit, MI; Riverside, CA; Sacramento, CA; Las Vegas, NV; Fresno, CA; Bakersfield, CA; McAllen, TX; Stockton, CA; Modesto, CA; (Low Unemployment MSAs) Washington, DC; Boston, MA; Minneapolis, MN; Oklahoma City, OK; Honolulu, HI; Tulsa, OK; Omaha, NE; Des Moines, IA; Madison, WI; Lancaster, PA.

${ }^{13}$ The online job board used in the experiment lists job postings by city rather than MSA, so we searched for appropriate jobs within 25 miles of the major city within the MSA.

${ }^{14}$ We always e-mailed the resumes from within the online job board website. We never e-mailed any of the employers directly.
} 
in this database. ${ }^{15}$ From this set of templates, we selected four templates (one per fictitious resume) according the following rule: if an RA applied to a given MSA and job category combination before, she reused the templates from that application. Otherwise, she randomly drew four new templates from the ten possible templates, drawing without replacement to ensure that no two resumes being sent to a given job share the same resume template. There are six more steps in designing a fictitious resume:

1. We decided whether each resume would be male or female. For Customer Service and Sales jobs, we sent two female and two male resumes. For Administrative/Clerical jobs, we sent four female resumes. This design decision follows the protocol of Bertrand and Mullainathan (2004).

2. We randomly generated a name for the resume. The bank of names were chosen based on common frequency census data and were chosen to be minimally informative about the race of the applicant.

3. We chose the home address, local phone number, and e-mail address. In general, we constructed local addresses based on addresses that were listed in the real resumes in the database of actual resumes described above, and we modified these addresses by choosing a non-existent street number. We purchased 400 unique local phone numbers (4 per MSA) which could each receive voice mail messages, and we created roughly 1,600 unique e-mail addresses to use in the experiment. ${ }^{16}$ Both the phone numbers and e-mail addresses allowed us to track callbacks on an ongoing basis.

4. The next step was updating the fictitious resume's job history, educational history and the objective summary to match the job that we applied to. Work histories were constructed from the sample of real resumes that we self-collected. For instance, if the job was for an Administrative Assistant position, we identified a resume with experience as an Administrative/Executive Assistant and used this to construct the work history. For resumes that were sent to jobs in the same MSA, we never shared work histories. In terms of education, we searched for large, local degree-granting institutions. Finally, we verified that there was not a real individual with a similar background on any of the major social network and job network websites (e.g., Facebook and LinkedIn).

5. We defined a measure of "quality" for each resume. A "low quality" resume is one that is assigned the minimum qualifications required for the job (in terms of experience and education). A "high quality" resume had qualifications that exceeded these minimum requirements. Specifically, these resumes had a couple of extra years of experience and an extra "level" of education. For instance, if the job requires high school completion, we would list an associate degree or if the job requires an associate degree, we would list a bachelor degree. For jobs that required a bachelor degree, we did not bump up the

\footnotetext{
${ }^{15}$ By "template" we mean the specific formatting and layout of the items on the resume (e.g., style of bullet points, ordering of items, etc.).

${ }^{16}$ As explained above, we re-use resumes when we can. When we do that, we re-use both the name and e-mail address.
} 
education level for the high quality resumes. For each job that we applied to, two resumes were low quality and two were high quality. This means we either had a set of fone high quality male, one high quality female, one low quality male, one low quality female\} or we had a set of two high-quality female resumes and two low-quality female resumes (depending on the gender ratio that the job category calls for).

6. The final and most important step was to randomize employment status and the length of the current unemployment spell. We describe the randomization procedure in more detail when we introduce the empirical model. The randomly drawn length of the unemployment spell for a given resume pins down the end date of the worker's last job, and hence the worker's prior job tenure. In most cases, we designed resumes so that the most recent job started in 2008 or earlier, so that we did not end up dropping a job when assigning long unemployment spells.

\subsection{Measuring Salience of Resume Characteristics}

Our field experiment assumes that the information on the resume regarding a job applicant's employment status and unemployment spell length is salient to employers. To test this assumption, we designed and conducted a web-based survey. A link to the survey was e-mailed to $365 \mathrm{MBA}$ students at the University of Chicago Booth School of Business. A total of 91 students completed the survey. This section summarizes the design and results of the survey; more details on the survey can be found in Appendix F.

The survey took place in three stages. First, respondents were asked to read a hypothetical job posting and to consider two resumes for the job opening (see Appendix Figure A1). The respondent was then asked to select one of the two resumes to contact for an in-person job interview. Second, once the respondent made a selection, she was then asked to recall specific information on the resume such as total work experience, tenure at last job, level of education, current employment status, and the length of unemployment spell (Appendix Figure A2). We use these responses to evaluate the extent to which the various characteristics on the resume are salient to subjects. Finally, we asked respondents several demographic questions; in particular, whether they had prior experience evaluating resumes (Appendix Figure A3).

To empirically measure salience, we rely on two proxies: (1) the fraction of time the respondents correctly recall the information, and (2) the correlation between the reported and true answers. As shown in Appendix Table A1, across both of our measures of salience, respondents are able to recall information about applicant's employment status and length of unemployment spell about as well as they are able to recall information about other resume characteristics (such as education, total work experience, and tenure at last job). When we restrict the sample to those that respond that they have "high experience" reviewing resumes (column (2)), respondents are more likely to correctly identify employment status and length of unemployment. Overall, these results suggest that employment status and length of unemployment are salient to those evaluating 
resumes, especially if they are experienced at evaluating resumes.

\subsection{Measuring Callbacks}

We track callbacks from employers by matching voice or e-mail messages to resumes. We follow Bertrand and Mullainathan (2004) by defining a callback as a message from an employer explicitly asking to set up an interview. The voicemail messages were coded independently by two Research Assistants (RAs) who were not otherwise involved in the project, and the two RAs agreed virtually all of the time. In Table 4, we report results which use an alternative definition of a callback based on whether the employer left any voice message at all, even if the message simply asked for more information. We always allowed at least six weeks for a callback, though in practice the the vast majority of callbacks were received in the first two weeks. Additionally, the vast majority of callbacks were voice messages; e-mail messages from employers asking to set up an interview were extremely rare.

\subsection{Empirical Models}

In terms of the experimental design, we created two treatment groups:

- Treatment 1: Individuals are randomly assigned to employment status "Employed" with probability 0.25. In this case, the resume indicates that the person is still working at her current job. Let $E_{i, c}$ denote an indicator variable that equals 1 if individual $i$ in MSA $c$ is employed and 0 otherwise.

- Treatment 2: Individuals that are not assigned to the Employed treatment are unemployed and randomly assigned an (integer) unemployment duration or "gap" (in months) according to a discrete uniform distribution on the interval $[1,36]$. Let $\log \left(d_{i, c}\right)$ denote the $\log$ of the unemployment duration for individual $i$ in MSA $c$. Employed individuals are assigned $\log \left(d_{i, c}\right)=0$.

To analyze the experimental data, we estimate the following linear probability model that includes, for efficiency gains, individual and MSA characteristics $X_{i, c}$ :

$$
y_{i, c}=\beta_{0}+\beta_{1} E_{i, c}+\beta_{2} \log \left(d_{i, c}\right)+X_{i, c} \Gamma+\varepsilon_{i, c}
$$

where $y_{i, c}$ is a callback indicator that equals 1 if individual $i$ in MSA $c$ receives a callback for an interview. Given our randomized design, the coefficients $\beta_{1}$ and $\beta_{2}$ provide unbiased estimates of the mean impact of being employed versus being newly unemployed and the mean impact of changes in unemployment duration conditional on being unemployed. Since the effect may differ in magnitude across different unemployment durations, we also report results using alternative functional forms. In particular, we examine the data nonparametrically by using moving averages and plot callback rates as a function of unemployment duration. 
To examine how duration dependence varies with local labor market conditions, we pursue two complementary approaches. First, we estimate fixed effects and (correlated) random effects models of the following form:

$$
y_{i, c}=\alpha_{1} E_{i, c}+\delta^{c}+\gamma^{c} \log \left(d_{i, c}\right)+X_{i, c} \Gamma+\varepsilon_{i, c}
$$

In the fixed effects model, $\delta^{c}$ is a MSA fixed effect and $\gamma^{c}$ is a MSA-specific estimate of the effect of unemployment duration on callbacks. In the random effects model, $\delta^{c}$ is a MSA random effect and $\gamma^{c}$ is a MSA-specific random coefficient on unemployment duration. This specification is directly motivated by our mechanical model which indicates that there is a one-to-one relationship between the intercept $\delta^{c}$ (i.e., the callback rate for a newly unemployed individual) and the level of market tightness. Therefore, the covariance between $\delta^{c}$ and $\gamma^{c}$ (i.e., $E\left[\left(\delta^{c}-\bar{\delta}^{c}\right) \gamma^{c}\right]$ ) indicates the extent to which duration dependence varies with market tightness. For the fixed effects model, we prove in the Appendix that an unbiased estimate of this covariance is given by the following expression:

$$
E\left[\left(\delta^{c}-\bar{\delta}^{c}\right) \gamma^{c}\right]=\frac{1}{C} \sum_{c=1}^{C} \hat{\delta}^{c} \hat{\gamma}^{c}+\frac{1}{C} \sum_{c=1}^{C} \frac{\hat{\sigma}_{c}^{2}}{N^{c}} \frac{E_{c}[\log (d)]}{\operatorname{Var}(\log (d))}
$$

where $C$ is the total number of cities in the sample, $\hat{\delta}^{c}$ and $\hat{\gamma}^{c}$ are the estimated MSA fixed effects and MSA-specific estimates of the effect of unemployment duration, $\hat{\sigma}_{c}^{2}$ is the estimated MSA-specific residual variance and $N^{c}$ is the number of observations in the MSA. The second term in equation (14) represents a bias correction to account for the negative mechanical correlation between the MSA-specific estimates $\hat{\delta}^{c}$ and $\hat{\gamma}^{c}$. Intuitively, the slope and intercept estimates in an OLS regression are correlated, so in order to obtain an unbiased estimator of the covariance of the estimated intercept and slope parameters across cities, we need to adjust for this "mechanical" bias using equation (14) above. We then convert the covariance estimate to a correlation by dividing by the standard deviation of the estimated MSA-specific interaction terms and the standard deviation of the estimated MSA fixed effects. ${ }^{17}$ For the random effects model, the covariance is estimated by specifying that $\delta^{c}$ and $\gamma^{c}$ are jointly normally distributed and estimating the variance-covariance parameters of the joint normal distribution.

Our second approach to estimating how duration dependence varies with market tightness uses proxies for market tightness $\left(x_{c}\right)$ to estimate the following linear probability model:

$$
y_{i, c}=\beta_{0}^{\prime}+\beta_{1}^{\prime} E_{i, c}+\beta_{2}^{\prime} \log \left(d_{i, c}\right)+\beta_{3}^{\prime} \log \left(d_{i, c}\right) \times x_{c}+\beta_{4}^{\prime} x_{c}+X_{i, c} \Gamma^{\prime}+\varepsilon_{i, c}
$$

This specification includes an interaction between log duration and the market tightness proxies. We explore several alternative proxies in the specifications below, including the metropolitan area unemployment rate

\footnotetext{
${ }^{17}$ We adjust the estimates of standard deviation of the interaction terms and city fixed effects by a "shrinkage factor" based on an estimate of the residual variance.
} 
and MSA-level estimates of the vacancy-unemployment ratio.

Finally, we examine how duration dependence varies with characteristics of the resumes, employers, and job postings. We do this by reporting results estimated for various subsamples based on these characteristics.

\section{$5 \quad$ Experimental Results}

Our final sample includes 12,054 resumes submitted to 3,040 jobs. ${ }^{18}$ Of these 12,054 resumes, 9,236 of the resumes had (ongoing) unemployment spells of at least one month, with the remaining 2,818 resumes conveying that the worker was currently employed. ${ }^{19}$ Table 1 reports descriptive statistics for the sample. About 13 percent of our resumes elicit some response by employers. However, not all of these are callbacks for interviews. About one-third of all callbacks were classified as callbacks for interviews, for a total callback rate of about 4.7 percent. In terms of demographics, roughly two-thirds of our resumes are female, and most of our resumes show relatively little experience. Mean experience is 5 years with a max of 15 years of experience. Compared to the types of jobs that individuals are applying to, the resume sample is fairly educated: one-third of the respondents have Bachelor's degrees. This is primarily due to our strategy of sending out both resumes that just match the minimum requirements and resumes that are of higher quality. Due the randomized design of the field experiment, there is balance across the covariates (across employed/unemployed and across the distribution of unemployment durations), as shown in Table 2.

\subsection{Estimating Duration Dependence}

\section{Nonparametric Evidence}

Before turning to regression results, we begin with a simple nonparametric plot of the average callback rate. Using the sample of unemployed individuals $(N=9,236)$, Figure 1 reports the relationship between the callback rate and unemployment duration. The dots in the figure report average callback rates across 3-4 month bins while the dashed line is a 5-month moving average computed at each month. Both the dots and the dashed line show clear visual evidence that callbacks decline sharply with unemployment duration for the first 6-8 months, and then the callback rate is flat for unemployment durations beyond that. Figure 2 shows a similar pattern using the ratio of the callback rate in each bin divided by the callback rate in the first bin (i.e., the lowest unemployment durations). This figure corresponds more closely to the function $r(d ; x)$ defined in Section 2 above. In Figure 3, we report nonparametric local linear regression results that are constrained to be weakly monotonic following the rearrangement procedure of Chernozhukov,

\footnotetext{
${ }^{18}$ Our power calculations called for 12,000 resume submissions. We needed to submit to more than 3,000 jobs to reach 12,000 resumes because there were several instances where the job posting was taken down before we were able to submit all four of the resumes prepared for the job. This happened on occasion because we waited one day between each resume submission for a given job posting. In total, we were not able to send four resumes to 46 jobs; these jobs received 78 resumes.

${ }^{19}$ The share of resumes currently employed is $23.4 \%$, which is less than $25 \%$ (which was the experimental protocol). The discrepancy comes from roughly 600 resumes where the employment status was randomized slightly differently (in particular, employment was chosen with $p=1 / 37$ rather than $p=0.25)$. All results are robust to dropping these observations.
} 
Fernandez-Val, and Galichon (2003). The bootstrapped standard errors in Figure 3 are uniform confidence intervals. We can visually reject the null hypothesis that there is no relationship between unemployment duration and callback rates based on the inability to draw any horizontal line through the plotted confidence intervals. Overall, all three of these figures show a clear negative relationship between callback rates and unemployment duration, with the steepest decline coming in the first eight months of the unemployment spell. This provides some of the first experimental evidence of negative duration dependence in callback rates, and it also helps to partially resolve the set of mixed and inconclusive empirical results from studies that are based on non-experimental approaches. Finally, the pattern of duration dependence in these figures suggest that human capital depreciation is unlikely the sole mechanism behind our results; for if it were, we would have expected callback rates to continue to decline beyond the eight month mark, as worker skills continue to erode. This suggests other factors at work, such as employer screening, which we investigate in more detail in the next subsection.

\section{Regression Results}

The regression results confirm the results from the graphical analysis. Table 3 reports OLS regression results estimating equation (12). Longer unemployment durations are associated with lower callback rates. A 1 log point change in unemployment duration is associated with a strongly statistically significant 1.1 percentage point decline in the callback probability, from a mean of 4.7 percentage points. This corresponds to a 23 percent decline in the callback rate. Surprisingly, the results in the second row suggest that employed applicants are actually less likely to receive callbacks (relative to newly unemployed individuals). We discuss possible explanations for this result at the end of this section. In the remaining columns, we investigate alternative functional forms. Column (2) reports results from a specification with unemployment duration in levels, while column (3) reports results using piecewise indicator variables for various groups of months (with months 0-6 as the omitted category). The pattern of coefficients in column (3) suggest a strong decline in callback probability after six months, and a negligible decline thereafter. Finally, column (4) reports results from a spline regression which allows for a structural break in the effect of unemployment duration at eight months (the location of the structural break is determined through auxiliary regressions which choose the location of the break to maximize the $R^{2}$ of the regression). The results in this column suggest that callbacks are sharply decreasing for the first eight months and nearly flat after that. ${ }^{20}$

Table 4 shows that results are robust to alternative specifications. First, we explore specifications where all controls are excluded or additional controls are added. ${ }^{21}$ Second, we estimate a Probit model to address

\footnotetext{
${ }^{20}$ Appendix Table A2 reports the estimated coefficients on the control variables used in all of the main tables, such as gender and "high quality" resume indicator. Additionally, Appendix Table A2 shows that when we drop city fixed effects and include the city unemployment rate as an additional control instead, we find that the unemployment rate strongly predicts callbacks. This is consistent with a large literature in labor economics which finds that aggregate labor market variables strongly predict individual unemployment duration (Petrolongolo and Pissarides 2001).

${ }^{21}$ The additional control variables that we add include the following: resume template and resume font fixed effects, year $\times$ week fixed effects, metropolitan area $\times$ job type fixed effects, and year $\times$ week $\times$ job type fixed effects.
} 
concerns about boundary effects that arise because of the low average callback rate. Lastly, we explore an alternative, more inclusive definition of employer callbacks. ${ }^{22}$ In all cases, we find results that are extremely similar to our main results.

\subsection{Duration Dependence and Labor Market Conditions}

We next turn to the question of how the relationship between callback rates and unemployment duration varies with market tightness. We begin by providing graphical evidence. Figures 4 and 5 show plots analogous to Figures 1 and 2, but they divide the sample depending on whether the local unemployment rate is above or below $8.8 \%$ (the median unemployment rate across cities in the experiment). As before, we first plot the raw callback rates (Figure 4) and then we plot the relative callback rate, the callback rate divided by average callback rate in the first "bin" (Figure 5), which corresponds to the function $r(d ; x)$ introduced in Section 2. As discussed in Section 3, the screening model implies that $\frac{\partial r(d ; x)}{\partial x}<0$ for all $d>0$, whereas the ranking model implies that $\frac{\partial r(d ; x)}{\partial x}>0$, and the human capital depreciation model implies that $\frac{\partial r(d ; x)}{\partial x}=0$. Figure 5 therefore allows us to discern among these models and it finds evidence in favor of the screening model: the relative callback rates always decline more rapidly in markets with lower unemployment. These patterns are robust to other proxies for labor market conditions. For example, Figures 6 and 7 show similar results when the sample is divided based on median ratio of vacancies to unemployment ( $V / U$ ratio), while Figures 8 and 9 show similar results when the sample is split based on whether the unemployment rate increased by more than 3.6 percentage points between 2008 and 2011 (the median percentage point increase across the cities in the experiment).

The regression evidence confirms the visual patterns in these figures. We begin with a simple test of whether there is heterogeneity in duration dependence across labor markets. Table 5 reports results which test whether the effect of unemployment duration on callbacks is the same across all metropolitan areas based on our fixed effects estimates from equation (13). We interact a full set of metropolitan area fixed effects with unemployment duration and conduct an F-test of equality across all of the estimated coefficients for these interaction terms. Based on the results in column (1), we confidently reject the null hypothesis that the effect of unemployment duration is the same across all metropolitan areas $(p=0.001)$. To test exactly how the effect of unemployment duration varies with market tightness, we construct an estimate of the correlation between the estimates of the MSA-specific interaction terms and the MSA fixed effects estimated in equation (13). Consistent with the results in Figures 4 through 9, we estimate a statistically significant negative correlation between $\delta^{c}$ and $\gamma^{c}$; i.e., $\operatorname{cor} \widehat{r\left(\delta^{c}, \gamma^{c}\right)}=-0.790$; s.e. $=0.187 .{ }^{23}$ Under the assumption that the MSA fixed effects are valid proxies for market tightness, these results imply that

\footnotetext{
${ }^{22}$ Additionally, we explore a specification which drops 83 jobs (comprising 330 resumes) that were posted by employers that we later deemed "questionable." These employers were flagged because we found evidence online that the employer was engaging in dishonest, deceptive, or illegal behavior.

${ }^{23}$ See Appendix $\mathrm{G}$ for details on constructing standard errors for inference.
} 
duration dependence is stronger (i.e., more negative) in tight labor markets, consistent with the predictions of the employer screening model. These results are also consistent with the pattern shown in Figure 10, which graphs the relationship between the estimated MSA-specific coefficient on unemployment duration (from the fixed effects regression estimated in column (1) of Table 5) against the MSA unemployment rate (at the start of the experiment). The positive relationship in the figure implies that MSAs with lower unemployment rates have stronger (i.e., more negative) duration dependence.

The remaining columns in Table 5 repeat this same exercise, reporting the covariance in equation (14), but replacing $\log (d)$ with other covariates in $X_{i, c} \cdot{ }^{24}$ Columns (2) and (3) test for similar hetereogeneous effects across labor markets for the effect of gender and "skill" (as measured by whether or not resume was "high quality"), and we find no evidence that the effect of either of these covariates varies across cities. Columns (4) and (5) show that the callback rate of customer service jobs and sales jobs (relative to admin/clerical jobs) varies strongly across cities. However, these effects are correlated with the average callback rate within the experiment to a much lesser extent, and the sign is not consistent across the two types of jobs. In particular, cities with higher average callback rates are not relatively more likely to call back applicants to customer service jobs or sales jobs, even though these jobs have higher average callback rates. We interpret this as evidence against a "mechanical" interpretation of our results in column (1): specifically, these results are inconsistent with low average callback rates in a MSA simply being associated with attenuating the effect of all covariates. In this case, one would expect that cities with higher average callback rates to also have higher callback rates for customer service jobs and sales jobs relative to Administrative/Clerical jobs, and we do not find evidence that this is the case.

Table 6 reports similar results based on estimating a correlated random coefficients model, where the regression model in equation (13) above is given an alternative interpretation: specifically, $\delta^{c}$ is assumed to be a MSA-specific random effect and $\gamma^{c}$ is a MSA-specific random coefficient on unemployment duration. The random coefficients are allowed to be flexibly correlated and assumed to be jointly normally distributed across cities. As in Table 5, we report whether we find evidence that the random coefficients on unemployment duration are statistically significantly different, and we also report estimates of the correlation between the random coefficient and the MSA-specific random effect. The results are qualitatively similar: for unemployment duration we estimate a significant negative correlation $\left(\operatorname{cor} \widehat{r\left(\delta^{c},\right.} \gamma^{c}\right)=-0.909$; s.e. $\left.=0.094\right)$, which implies that cities with higher average callback rates within the experiment have stronger duration dependence.

Our final test of how duration dependence varies with labor market conditions uses two proxies for local labor market tightness: the unemployment rate and the vacancy-to-unemployment $(V / U)$ ratio. When using the unemployment rate as proxy for labor market tightness, we use the monthly unemployment rate in the

\footnotetext{
${ }^{24}$ When we replace $\log (d)$ with one of the covariates in $X_{i, c}$, we place $\log (d)$ in $X_{i, c}$ vector.
} 
metropolitan area at the start of the experiment (July 2011) from the BLS. The $V / U$ ratio is constructed using data on vacancies from the Help Wanted Online Index and data on the number of unemployed from the BLS. Table 7 reports the OLS estimates of equation (15) using these proxies for labor market tightness. Using several alternative functional forms for the unemployment rate and the $V / U$ ratio, we consistently estimate that the effect of unemployment duration is stronger when the local labor market is relatively tight (i.e., either the unemployment rate is relatively high or the $V / U$ ratio is relatively low). Panels $\mathrm{B}$ and $\mathrm{C}$ in Table 7 verify that the estimated interaction terms are robust to including both MSA fixed effects as well as a wide range of interactions between unemployment duration and MSA characteristics (e.g., population, GDP, income, fraction of population with Bachelor's degree, fraction of employed workers in Information industries). The robustness to including these additional interactions confirms that the interaction effects of interest are not confounded by other metropolitan area characteristics that are correlated with labor market tightness. In Appendix Table A3, we report results analogous to Panel A in Table 7 replacing the OLS (linear probability) model with a Probit model and a fixed-effects Poisson model. The Probit results show that the estimated marginal effects are very similar to the OLS results, while the Poisson model provides results which can be interpreted as "proportional effects." These results therefore verify that duration dependence declines proportionally with the unemployment rate, which is consistent with the Figures 5, 7, and 9 that show that the "relative" callback rate declines more sharply in tighter labor markets.

Our findings indicate that duration dependence is stronger when the unemployment rate is relatively low, consistent with the screening model. Interestingly, this implies that there are two competing effects of a higher unemployment rate: First, a higher unemployment rate has a direct effect making it harder for workers to match with firms and causing longer spells. Second, a higher unemployment rate has an indirect effect since it leads to less screening by firms, and less duration dependence in equilibrium. In column (1) in Panel A, the standardized effect of the unemployment rate implies that a one standard deviation increase in the unemployment rate reduces the callback rate by 0.77 percentage points (from a mean of 4.7 percent). This same change reduces the coefficient on unemployment duration by 0.0044 (i.e., from -0.012 to -0.0076$)$.

One question we can ask to shed light on the relative importance of these two effects is how long a duration it takes the callback rate in a strong labor markets to fall to the level of that in a weak labor market.. We use the standardized effects in column (1) of Table 7 (Panel A) to solve for the unemployment duration that equalizes expected callback rates across two labor markets that have unemployment rates one standard deviation above and below mean, respectively. We find that at roughly six months of unemployment, expected callback rates are similar across these two labor markets, despite having differences in unemployment rates of roughly 5 percentage points and significant differences in expected callback rates for newly unemployed workers ( 5.5 percent versus 3.9 percent). The callback rates equalize across weak and 
strong markets because duration dependence is significantly stronger in tight labor markets. After several months of unemployment, the expected callback rate has fallen much more in the tight labor market as compared to the weak labor market.

\subsection{Heterogeneity by Resume Characteristics and Employer/Job Characteristics}

Tables 8 and 9 explore whether duration dependence varies with resume characteristics and employer/job characteristics, respectively. The point estimates in Table 8 suggest similar levels of duration dependence across education categories (columns (4) and (5)) and skill groups (columns (6) and (7)), and somewhat larger duration dependence estimates for women as compared to men (columns (2) and (3)), although this difference is not statistically significant at conventional levels. Turning to employer/job characteristics in Table 9, our estimates in columns (2) and (4) indicate that duration dependence is strongest for workers applying to Sales jobs (as compared to Administrative/Clerical jobs and Customer Service jobs), although these differences are not statistically significant. In columns (5) through (7), we compare estimates of duration dependence across industries, and we find that our overall duration dependence estimates are concentrated in Construction, Manufacturing, and Wholesale and Retail Trade, with no significant evidence of duration dependence in Business/Financial Services or Professional/Personal Services. The remaining columns explore differences according to whether the job posting mentions that experience is required and whether the posting explicitly mentions that the employer is an Equal Opportunity Employer. In both of these cases, there are no significant differences across the subsamples.

Finally, we return to our suggestive evidence in Table 3 that an individual who is currently employed is actually less likely to be called back for an interview than a newly unemployed individual. In discussions with human resource professionals, we have learned that some employers express the concern that workers who are currently employed are not serious job seekers, and as a result, are less likely to invite them in for an interview, which would be consistent with these findings. Additionally, we speculate that our findings could also be caused by the fact that some jobs require workers to start immediately. In this case, it's possible that the lag in recruiting a worker who is currently employed exceeds the lag in hiring a job seeker who is currently out of work, which may be particularly relevant for the set of less-skilled jobs that are posted on the online website that we use for the experiment.

\section{Conclusion}

This paper discusses results from a field experiment studying duration dependence. Our results suggest that the likelihood of receiving a callback sharply declines with unemployment duration. This effect is especially pronounced during the first eight months after becoming unemployed. Our estimates suggest that this effect is quantitatively important, and, additionally, our results suggest that duration dependence is stronger when 
jobs are relatively abundant.

Our conceptual framework shows that these results are consistent with a model where employers statistically discriminate against workers with longer unemployment durations. Our results are not easily generated by a model of human capital depreciation when the rate of human capital depreciation is steady and the same across labor markets nor are they consistent with a model of duration dependence based on a simple model of employer ranking (Blanchard and Diamond 1994). Although we emphasize that we do not rule out the existence of these other mechanisms, our results are most consistent with employer screening playing an important role in generating duration dependence.

The results in our experiment suggest several additional areas for future research. Empirically, we think it is important to examine whether our results generalize to the economy more broadly. Future audit studies might explore whether duration dependence varies across occupations or over time. Such studies might also expand the coverage to a broader segment of the economy where online job search is less prevalent.

Theoretically, there are close connections between the screening model that is supported by our data and the literature on rational herding that bear exploring. ${ }^{25}$ Our screening model assumes that employers meet workers sequentially. Employers then use the information about prior actions of other firms, embedded in the duration of unemployment, to learn about worker productivity. However, they do not observe the private signals received by the other firms. This structure is very similar to the structure of the standard rational herding model. ${ }^{26}$ In ongoing work, we are exploiting the insights of the rational herding literature to study the policy implications of our findings. In herding models, if the public belief is sufficiently strong, agents will ignore their private information and end up in informational cascades where no further learning takes place. From the standpoint of social welfare, such cascades are sub-optimal, since they imply that information does not aggregate. We study the conditions that give rise to informational cascades in our setting and ask whether a social planner would want to distort firms' hiring decisions to avoid such cascades. We also explore the implications of the screening model for the optimal design of Unemployment Insurance (UI) benefits, in order to examine the optimal time path of UI benefits in an environment with asymmetric information and social learning. ${ }^{27}$

\footnotetext{
${ }^{25}$ For a review of herding models, see Bikhchandani et al (1998).

${ }^{26}$ The main difference is an asymmetry in the learning process that is present in our model: once a worker is hired by a firm, the public learning process stops.

${ }^{27}$ For related studies on the optimal design of UI benefits, see Shavell and Weiss (1979), Shimer and Werning (2006, 2008) and Pavoni 2009.
} 


\section{References}

Acemoglu, Daron (1995). "Public Policy in a Model of Long-term Unemployment," Economica, 62(246), 161-178.

Bertrand, Marianne and Sendhil Mullainathan (2004) "Are Emily and Greg More Employable than Lakisha and Jamal? A Field Experiment on Labor Market Discrimination," American Economic Review, 94(4), 991-1013.

Bikhchandani, Sushil, David Hirshleifer, and Ivo Welch (1998). "Learning from the behavior of others," Journal of Economic Perspectives, 12: 151-170.

Blanchard, Olivier J. and Peter Diamond (1994). "Ranking, Unemployment Duration, and Wages," Review of Economic Studies, 61(3), 417-434.

Chernozhukov, Victor, Ivan Fernandez-Val, and Alfred Galichon (2009). "Improving Estimators of Monotone Functions by Rearrangement." Biometrika, 96(3): 559-575.

Congressional Budget Office (2012). "Understanding and Responding to Persistently High Unemployment." http://www.cbo.gov/publication/42989.

Eriksson, Stefan and Dan-Olof Rooth (2011). "Do Employers Use Unemployment as a Sorting Criterion When Hiring? Evidence from a Field Experimen." Unpublished manuscript.

Felstein, Martin and James Poterba (1984). "Unemployment insurance and reservation wages," Journal of Public Economics, 23(1), 141-167

Gonzales, Fracisco M. and Shouyong Shi (2010). "An equilibrium theory of learning, search, and wages." Econometrica, 509-537.

Heckman, James J. and Burton Singer (1984). "The Identifiability of the Proportional Hazard Model," Review of Economic Studies, 51(2), 231-241.

Imbens, G. and L. Lynch (2006). "Re-employment probabilities over the business cycle," Portuguese Economic Journal, 5(2): 111-134.

Krueger, Alan B. and Andreas Mueller (2011). "Job Search and Job Finding in a Period of Mass Unemployment: Evidence from High-Frequency Longitudinal Data," Unpublished manuscript, Princeton University.

Lahey, Joanna N. (2008). "Age, Women, and Hiring: An Experimental Study," Journal of Human Resources, 43(1), 30-56.

Ljungqvist and Sargent (1998). "The European unemployment dilemma." Journal of Political Economy, 106(3), 514-550.

Lockwood, Ben (1991). "Information Externalities in the Labor Market and the Duration of Unemployment," Review of Economic Studies, 58(4), 733-753.

Machin, Stephen and Manning, Alan (1998). "The causes and consequences of long-term unemployment in Europe," CEPDP, 400. Centre for Economic Performance, London School of Economics and Political Science, London, UK.

Moscarini, Giuseppe (1997). "Unobserved heterogeneity and unemployment duration: a fallacy of composition", Yale University Working Paper.

Oberholzer-Gee, Felix (2008). "Nonemployment stigma as rational herding: A field experiment," Journal of Economic Behavior $\& 3$ Organization, 65, 30-40.

Oreopoulos, Philip (2011) "Why Do Skilled Immigrants Struggle in the Labor Market? A Field Experiment with Thirteen-Thousand Resumes." American Economic Journal: Economic Policy (forthcoming).

Pavoni, Nicola (2009). "Optimal Unemployment Insurance, With Human Capital Depreciation, and Duration Dependence," International Economic Review, 50(2): 323-362. 
Petrongolo, Barbara and Christopher A. Pissarides (2001). "Looking into the Black Box: A Survey of the Matching Function," Journal of Economic Literature, 39: 390-431.

Sahin, Aysegul, Joseph Song, Giorgio Topa, and Giovanni Violante (2011), "Measuring Mismatch in the U.S. Labor Market", NY Fed Working Paper.

Shavell, Steven and L. Weiss (1979), "The optimal payment of unemployment insurance benefits over time," Journal of Political Economy, 87(6): 1347-62.

Shimer, Robert and Ivan Werning (2008). "Liquidity and Insurance for the Unemployed," American Economic Review, 98(5): 1922-42.

Shimer, Robert and Ivan Werning (2006). "On the Optimal Timing of Benefits with Heterogeneous Workers and Human Capital Depreciation," Unpublished manuscript.

Van den Berg, Gerard J. and Jan C. van Ours (1996). "Unemployment Dynamics and Duration Dependence." Journal of Labor Economics, 14(1): 100-125.

Vishwanath, T. (1989). "Job Search, Stigma Effect, and Escape Rate from Unemployment," Journal of Labor Economics, 7(4):487-502. 


\section{Table 1}

Descriptive Statistics

\begin{tabular}{lccccc}
\hline \hline & & & & & \\
& $\mathrm{N}$ & Mean & Std. Dev. & Min & Max \\
\hline Received callback for interview & 12054 & 0.047 & 0.212 & 0 & 1 \\
Received any phone call from employer & 12054 & 0.126 & 0.331 & 0 & 1 \\
Employed & 12054 & 0.234 & 0.423 & 0 & 1 \\
Months unemployed | Unemployed & $\mathbf{9 2 3 6}$ & $\mathbf{1 8 . 0 1 8}$ & $\mathbf{1 0 . 3 0 3}$ & $\mathbf{1}$ & $\mathbf{3 6}$ \\
Associate degree & 12054 & 0.416 & 0.493 & 0 & 1 \\
Bachelor's degree & 12054 & 0.386 & 0.487 & 0 & 1 \\
High quality & 12054 & 0.502 & 0.500 & 0 & 1 \\
Female & 12054 & 0.637 & 0.481 & 0 & 1 \\
Years of experience & 12054 & 5.381 & 2.012 & 1 & 15 \\
Unemployment rate & 12054 & 9.364 & 2.481 & 5.07 & 17.03 \\
Vacanices/Unemployed ratio & 12054 & 3.796 & 1.581 & 0.80 & 7.47 \\
Administrative/Clerical job & 12054 & 0.293 & 0.455 & 0 & 1 \\
Customer Service job & 12054 & 0.306 & 0.461 & 0 & 1 \\
Sales job & 12054 & 0.401 & 0.490 & 0 & 1 \\
\hline \hline
\end{tabular}

Notes: The first row reports the primary dependent variable which is whether or not the resume received a callback from the employer explicitly asking to set up an interview. The experimental sample is split into resumes where the worker reports currently being employed and resumes where the worker does not report currently being employed (with the gap between when the worker last reported working and when the resume was submitted being uniformly distributed between 1 and 36 months, inclusive). The omitted education category is high school graduate. 


\section{Table 2}

Randomization Tests

\begin{tabular}{|c|c|c|c|c|c|c|}
\hline & \multicolumn{2}{|c|}{ Sample means } & \multirow{2}{*}{$\begin{array}{c}\text { p-value of } \\
\text { difference } \\
\text { in means }\end{array}$} & \multicolumn{2}{|c|}{ Sample means } & \multirow{2}{*}{$\begin{array}{l}\text { p-value of } \\
\text { difference } \\
\text { in means }\end{array}$} \\
\hline & Employed & Unemployed & & $\begin{array}{l}\text { Unemployed } \\
\geq 18 \text { months }\end{array}$ & $\begin{array}{l}\text { Unemployed } \\
<18 \text { months }\end{array}$ & \\
\hline Some college & 0.408 & 0.419 & 0.267 & 0.422 & 0.415 & 0.624 \\
\hline College degree & 0.402 & 0.381 & 0.217 & 0.389 & 0.373 & 0.276 \\
\hline High quality & 0.506 & 0.501 & 0.630 & 0.504 & 0.497 & 0.533 \\
\hline Female & 0.629 & 0.639 & 0.335 & 0.630 & 0.648 & $0.062 *$ \\
\hline Unemployment rate & 9.382 & 9.359 & 0.971 & 9.348 & 9.370 & 0.749 \\
\hline Vacancies/Unemployed ratio & 3.740 & 3.813 & 0.373 & 3.797 & 3.829 & 0.740 \\
\hline Administrative/Clerical job opening & 0.298 & 0.291 & 0.553 & 0.293 & 0.289 & 0.735 \\
\hline Customer Service job opening & 0.304 & 0.307 & 0.708 & 0.309 & 0.305 & 0.673 \\
\hline Sales job opening & 0.397 & 0.402 & 0.838 & 0.398 & 0.406 & 0.469 \\
\hline $\mathrm{N}$ & 2818 & 9236 & & 4650 & 4586 & \\
\hline
\end{tabular}

Notes: This table reports means across subsamples of the experimental sample and presents simple randomization tests based on t-tests. 
Table 3

The Effect of Unemployment Duration on Probability of Callback

\begin{tabular}{|c|c|c|c|c|}
\hline \multicolumn{5}{|c|}{ Dependent variable: Received callback for interview } \\
\hline & $(1)$ & $(2)$ & (3) & $(4)$ \\
\hline \multirow[t]{3}{*}{$\log$ (Months unemployed) } & -0.011 & & & \\
\hline & $(0.003)$ & & & \\
\hline & {$[0.000]$} & & & \\
\hline \multirow[t]{3}{*}{$\mathbf{1}\{$ Employed $\}$} & -0.020 & -0.004 & -0.016 & -0.035 \\
\hline & $(0.010)$ & $(0.006)$ & $(0.008)$ & $(0.013)$ \\
\hline & [0.040] & [0.556] & [0.043] & [0.005] \\
\hline \multirow[t]{3}{*}{ Months unemployed / 12} & & -0.008 & & -0.074 \\
\hline & & $(0.003)$ & & $(0.021)$ \\
\hline & & [0.002] & & {$[0.000]$} \\
\hline \multirow[t]{3}{*}{$6<$ Months unemployed $\leq 12$ | Unemployed } & & & -0.032 & \\
\hline & & & $(0.009)$ & \\
\hline & & & {$[0.000]$} & \\
\hline \multirow[t]{3}{*}{$12<$ Months unemployed $\leq 24$ | Unemployed } & & & -0.030 & \\
\hline & & & $(0.008)$ & \\
\hline & & & {$[0.000]$} & \\
\hline \multirow[t]{3}{*}{$24<$ Months unemployed | Unemployed } & & & -0.029 & \\
\hline & & & $(0.008)$ & \\
\hline & & & {$[0.000]$} & \\
\hline \multirow[t]{3}{*}{ Months unemployed / $12 \times \mathbf{1}\{$ Months unemployed $>8\}$} & & & & 0.074 \\
\hline & & & & $(0.022)$ \\
\hline & & & & {$[0.001]$} \\
\hline Joint significance of piecewise coefficients (p-value) & & & {$[0.001]$} & \\
\hline F-test of equality across piecewise coefficiets (p-value) & & & [0.933] & \\
\hline Average callback rate & 0.047 & 0.047 & 0.047 & 0.047 \\
\hline $\mathrm{N}$ & 12054 & 12054 & 12054 & 12054 \\
\hline $\mathrm{R}^{2}$ & 0.038 & 0.037 & 0.039 & 0.039 \\
\hline Metropolitan area fixed effects & $\mathrm{X}$ & $\mathrm{X}$ & $\mathrm{X}$ & $\mathrm{X}$ \\
\hline Baseline controls & $\mathrm{X}$ & $\mathrm{X}$ & $\mathrm{X}$ & $\mathrm{X}$ \\
\hline
\end{tabular}

Notes: All columns report OLS linear probability model estimates. Data are resume submissions matched to callbacks from employers to request an interview. The baseline controls included are the following: indicator variables for Associate degree, Bachelor's Degree, High quality resume, Female gender, and three job categories. Standard errors, adjusted to allow for an arbitrary variance-covariance matrix for each job posting, are in parentheses and p-values are in brackets. 
Table 4

Robustness Tests

\begin{tabular}{|c|c|c|c|c|c|c|c|c|c|c|}
\hline & $(1)$ & $(2)$ & (3) & (4) & (5) & $(6)$ & $(7)$ & $(8)$ & $(9)$ & $(10)$ \\
\hline \multirow[t]{3}{*}{ log(Months unemployed) } & -0.011 & -0.012 & -0.012 & -0.010 & -0.011 & -0.011 & -0.011 & -0.011 & -0.010 & -0.014 \\
\hline & $(0.003)$ & $(0.003)$ & $(0.003)$ & $(0.002)$ & $(0.003)$ & $(0.003)$ & $(0.003)$ & $(0.003)$ & $(0.003)$ & $(0.004)$ \\
\hline & {$[0.000]$} & {$[0.000]$} & {$[0.000]$} & {$[0.000]$} & {$[0.000]$} & {$[0.000]$} & {$[0.001]$} & {$[0.000]$} & {$[0.001]$} & {$[0.001]$} \\
\hline \multirow[t]{3}{*}{$\mathbf{1}\{$ Employed $\}$} & -0.020 & -0.023 & -0.025 & -0.017 & -0.020 & -0.020 & -0.019 & -0.019 & -0.017 & -0.009 \\
\hline & $(0.010)$ & $(0.010)$ & $(0.010)$ & $(0.006)$ & $(0.007)$ & $(0.010)$ & $(0.010)$ & $(0.009)$ & (0.009) & (0.013) \\
\hline & {$[0.040]$} & {$[0.019]$} & {$[0.012]$} & {$[0.005]$} & {$[0.002]$} & {$[0.041]$} & {$[0.045]$} & {$[0.048]$} & {$[0.063]$} & {$[0.491]$} \\
\hline Average callback rate & 0.047 & 0.047 & 0.047 & 0.047 & 0.047 & 0.047 & 0.047 & 0.047 & 0.044 & 0.126 \\
\hline $\mathrm{N}$ & 12054 & 12054 & 12054 & 12054 & 12054 & 12054 & 12054 & 12054 & 11724 & 12054 \\
\hline $\mathrm{R}^{2}$ & 0.038 & 0.015 & 0.002 & & & 0.039 & 0.054 & 0.093 & 0.036 & 0.069 \\
\hline Dependent variable: callback for interview & $\mathrm{X}$ & $\mathrm{X}$ & $\mathrm{X}$ & $\mathrm{X}$ & $\mathrm{X}$ & $\mathrm{X}$ & $\mathrm{X}$ & $\mathrm{X}$ & $\mathrm{X}$ & \\
\hline Dependent variable: receive any callback & & & & & & & & & & $\mathrm{X}$ \\
\hline Linear probability model & $\mathrm{X}$ & $\mathrm{X}$ & $\mathrm{X}$ & & & $\mathrm{X}$ & $\mathrm{X}$ & $\mathrm{X}$ & $\mathrm{X}$ & $\mathrm{X}$ \\
\hline Probit model (reported marginal effects at means of controls) & & & & $\mathrm{X}$ & $\mathrm{X}$ & & & & & \\
\hline Baseline controls & $\mathrm{X}$ & $\mathrm{X}$ & & $\mathrm{X}$ & & $\mathrm{X}$ & $\mathrm{X}$ & $\mathrm{X}$ & $\mathrm{X}$ & $\mathrm{X}$ \\
\hline Metropolitan area fixed effects & $\mathrm{X}$ & & & & & $\mathrm{X}$ & $\mathrm{X}$ & $\mathrm{X}$ & $\mathrm{X}$ & $\mathrm{X}$ \\
\hline Resume template and resume font fixed effects & & & & & & $\mathrm{X}$ & $\mathrm{X}$ & $\mathrm{X}$ & & \\
\hline Year $\times$ week fixed effects & & & & & & & $\mathrm{X}$ & $\mathrm{X}$ & & \\
\hline Metropolitan area $\times$ job type fixed effects & & & & & & & & $\mathrm{X}$ & & \\
\hline Year $\times$ week $\times$ job type fixed effects & & & & & & & & $\mathrm{X}$ & & \\
\hline Drop job postings from questionable employers & & & & & & & & & $\mathrm{X}$ & \\
\hline
\end{tabular}

Notes: Data are resume-level submissions matched to callbacks from employers to request an interview. Standard errors, adjusted to allow for an arbitrary variancecovariance matrix for each employment advertisement, are in parentheses and p-values are in brackets. 
Table 5

Heterogeneity by Local Labor Market: Fixed Effects Estimates

\begin{tabular}{|c|c|c|c|c|c|}
\hline \multicolumn{6}{|c|}{ Dependent variable: Received callback for interview } \\
\hline & $\begin{array}{c}\log (d) \\
(1)\end{array}$ & $\begin{array}{c}\text { Female } \\
\text { (2) }\end{array}$ & $\begin{array}{l}\text { ariate } \boldsymbol{X}=\text {. } \\
\text { High } \\
\text { quality } \\
\text { (3) }\end{array}$ & $\begin{array}{l}\text { Customer } \\
\text { service } \\
\text { job } \\
\text { (4) }\end{array}$ & $\begin{array}{c}\text { Sales } \\
\text { job } \\
(5)\end{array}$ \\
\hline $\begin{array}{l}\text { Point estimate on } \boldsymbol{X} \\
\text { (From model without interactions) }\end{array}$ & $\begin{array}{c}-0.011 \\
(0.003) \\
{[0.000]}\end{array}$ & $\begin{array}{r}0.002 \\
(0.004) \\
{[0.529]}\end{array}$ & $\begin{array}{r}0.011 \\
(0.004) \\
{[0.010]}\end{array}$ & $\begin{array}{r}0.029 \\
(0.006) \\
{[0.000]}\end{array}$ & $\begin{array}{r}0.057 \\
(0.007) \\
{[0.000]}\end{array}$ \\
\hline $\begin{array}{l}\text { F-test of equality for interaction terms (p-value) } \\
\text { (MSA fixed effect } \times \boldsymbol{X} \text { ) }\end{array}$ & [0.001] & [0.311] & [0.910] & {$[0.000]$} & [0.000] \\
\hline $\begin{array}{l}\text { Correlation between MSA fixed effect and } \\
\text { MSA-specific interaction term (bias-corrected) }\end{array}$ & $\begin{array}{r}-0.790 \\
(0.187) \\
{[0.000]}\end{array}$ & 0 & 0 & $\begin{array}{c}-0.466 \\
(0.230) \\
{[0.043]}\end{array}$ & $\begin{array}{r}0.012 \\
(0.244) \\
{[0.961]}\end{array}$ \\
\hline $\mathrm{N}$ & 12054 & 12054 & 12054 & 12054 & 12054 \\
\hline $\mathrm{R}^{2}$ & 0.083 & 0.083 & 0.083 & 0.083 & 0.083 \\
\hline
\end{tabular}

Notes: All columns report OLS linear probability model estimates. Data are resume-level submissions matched to callbacks from employers to request an interview, restricting sample to unemployed workers. Each column reports results from two separate regressions. The first row reports the point estimate on the covariate included in the column heading, when the effect is constrained to be the same across all MSAs. The second and third row report results from an alternative regression; specifically, it estimates a full set of interaction terms formed by multiplying indicator variable for each MSA with the variable listed in the column heading. The second row reports p-value from a test of equality across all of the estimated interaction terms, while the third row reports a bias-corrected estimate of the correlation between the estimated interaction terms and the MSA fixed effects. All regressions include same controls listed in Table 3 . If a cell entry has " 0 " with no standard error or p-value, then this implies that the model does not reject the null that the effect of the variable in the column is the same in all MSAs. Standard errors, adjusted to allow for an arbitrary variance-covariance matrix for each employment advertisement, are in parentheses and p-values are in brackets. 


\section{Table 6}

Heterogeneity by Local Labor Market: Correlated Random Effects Estimates

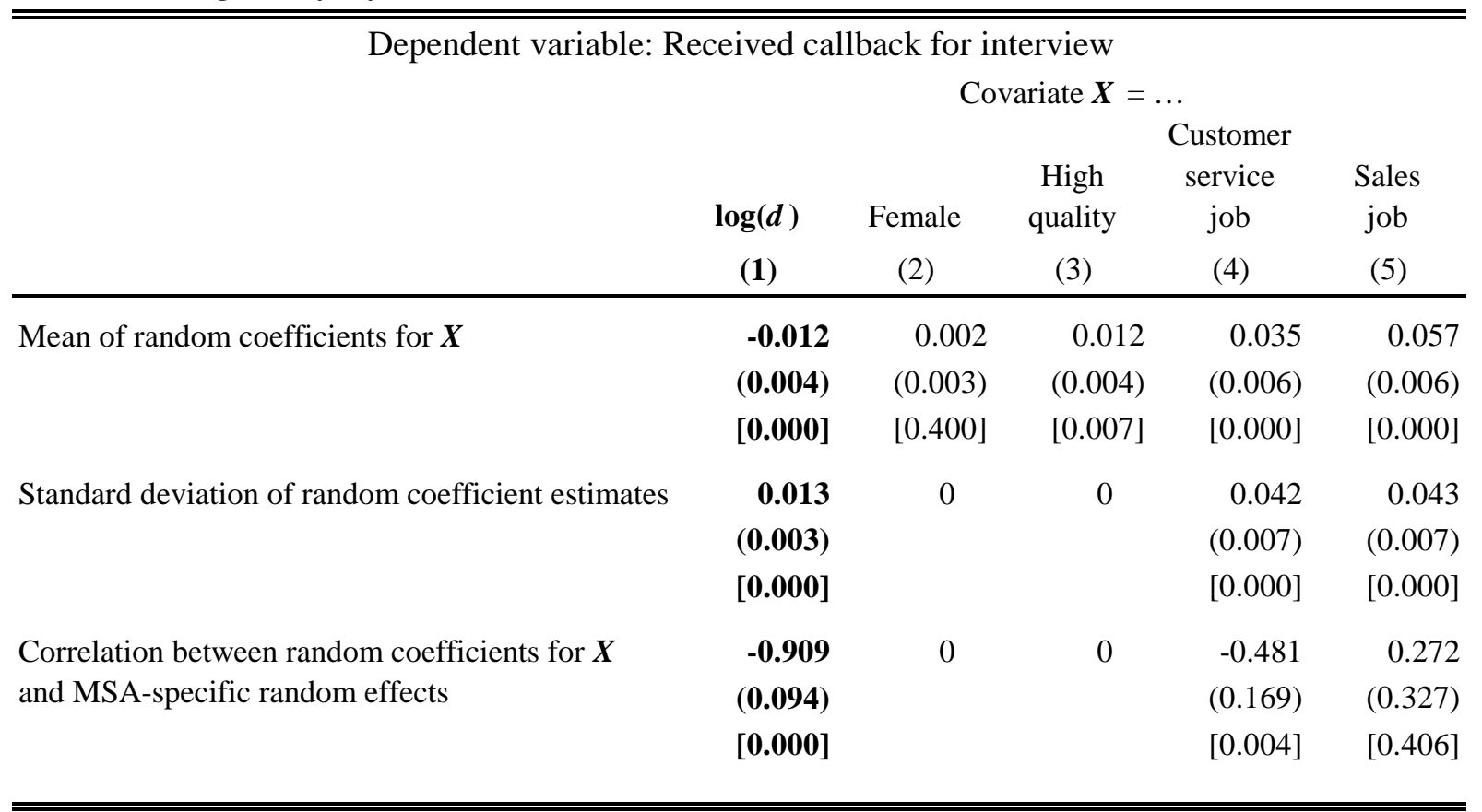

Notes: All columns report correlated random effects estimates, where a random coefficicent on the variable listed in the column is allowed to be flexibly correlated with a MSA-specific random effect parmaeter. The random coefficients are allowed to vary across cities but are constant within a MSA. Data are resume-level submissions matched to callbacks from employers to request an interview, restricting sample to unemployed workers. Each column reports results from a separate regression. The first row reports the mean of the random coefficients estimated on the variable in column heading. The second row reports the standard deviation across the random coefficient estimates. The final row reports the correlation between the random coefficient estimates and the MSA-specific random effect estimates. Standard errors, adjusted to allow for an arbitrary variancecovariance matrix for each employment advertisement, are in parentheses and p-values are in brackets. If a cell entry has "0" with no standard error or p-value, then this implies that the model does not reject the null that the effect of the variable in the column is the same in all cities. In the case, the model does not estimate MSAspecific random coefficients for variable in column, and instead only estimates MSA-specific random effects. 
Table 7

How Does Duration Dependence Vary With Labor Market Conditions?

\begin{tabular}{|c|c|c|c|c|c|}
\hline \multicolumn{6}{|c|}{ Dependent variable: Received callback for interview } \\
\hline & \multicolumn{5}{|c|}{$\begin{array}{c}\text { Interaction term formed using proxy for } \\
\text { local labor market conditions, } \boldsymbol{X}=\ldots\end{array}$} \\
\hline & \multicolumn{3}{|c|}{$u_{2011}-$} & \multirow{3}{*}{$\begin{array}{r}-V / U \\
(4) \\
\end{array}$} & \multirow{3}{*}{$\begin{array}{c}-\log (V / U) \\
(5)\end{array}$} \\
\hline & $u$ & $u_{2008}$ & $\log (u)$ & & \\
\hline & $(1)$ & $(2)$ & $(3)$ & & \\
\hline \multicolumn{6}{|c|}{$\underline{\text { Panel A: Include baseline controls only }}$} \\
\hline \multirow[t]{3}{*}{ log(Months unemployed) } & -0.012 & -0.012 & -0.012 & -0.012 & -0.012 \\
\hline & $(0.003)$ & $(0.003)$ & $(0.003)$ & $(0.003)$ & $(0.003)$ \\
\hline & {$[0.000]$} & {$[0.000]$} & {$[0.000]$} & {$[0.000]$} & [0.000] \\
\hline \multirow[t]{3}{*}{$\log ($ Months unemployed $) \times X$} & 0.176 & 0.341 & 0.020 & 0.003 & 0.009 \\
\hline & $(0.066)$ & $(0.124)$ & $(0.007)$ & $(0.001)$ & $(0.004)$ \\
\hline & {$[0.008]$} & {$[0.006]$} & {$[0.002]$} & {$[0.001]$} & [0.011] \\
\hline \multirow[t]{3}{*}{$\boldsymbol{X} \quad$ [Proxy for local labor market conditions] } & -0.311 & -0.532 & -0.034 & -0.005 & -0.018 \\
\hline & $(0.114)$ & $(0.214)$ & $(0.012)$ & $(0.002)$ & $(0.007)$ \\
\hline & {$[0.006]$} & {$[0.013]$} & {$[0.004]$} & {$[0.005]$} & [0.006] \\
\hline Standardized effect of interaction term & 0.0044 & 0.0043 & 0.0053 & 0.0055 & 0.0040 \\
\hline Standardized effect of $X$ & -0.0077 & -0.0068 & -0.0087 & -0.0085 & -0.0078 \\
\hline \multicolumn{6}{|c|}{ Panel B: Include baseline controls + MSA fixed effects } \\
\hline \multirow[t]{3}{*}{$\log ($ Months unemployed) } & -0.011 & -0.011 & -0.011 & -0.011 & -0.011 \\
\hline & $(0.003)$ & $(0.003)$ & $(0.003)$ & $(0.003)$ & $(0.003)$ \\
\hline & {$[0.000]$} & {$[0.000]$} & {$[0.000]$} & {$[0.000]$} & [0.000] \\
\hline \multirow[t]{3}{*}{$\log ($ Months unemployed $) \times \boldsymbol{X}$} & 0.168 & 0.329 & 0.020 & 0.003 & 0.009 \\
\hline & $(0.067)$ & $(0.123)$ & $(0.007)$ & $(0.001)$ & $(0.004)$ \\
\hline & [0.012] & [0.007] & [0.003] & [0.003] & [0.019] \\
\hline Standardized effect of interaction term & 0.0042 & 0.0042 & 0.0051 & 0.0052 & 0.0037 \\
\hline \multicolumn{6}{|c|}{ Panel C: Include baseline controls + MSA FEs + MSA characteristics $\times \log ($ Months unemployed) } \\
\hline \multirow[t]{3}{*}{$\log ($ Months unemployed) } & -0.011 & -0.011 & -0.011 & -0.011 & -0.011 \\
\hline & $(0.003)$ & $(0.003)$ & $(0.003)$ & $(0.003)$ & $(0.003)$ \\
\hline & {$[0.000]$} & {$[0.000]$} & {$[0.000]$} & {$[0.000]$} & {$[0.000]$} \\
\hline \multirow[t]{3}{*}{$\log ($ Months unemployed $) \times X$} & 0.257 & 0.384 & 0.030 & 0.005 & 0.014 \\
\hline & $(0.101)$ & $(0.169)$ & $(0.010)$ & $(0.002)$ & $(0.006)$ \\
\hline & [0.011] & {$[0.023]$} & {$[0.003]$} & [0.005] & [0.022] \\
\hline Standardized effect of interaction term & 0.0064 & 0.0049 & 0.0079 & 0.0079 & 0.0060 \\
\hline $\begin{array}{l}\text { p-value of F-test of joint significance } \\
\text { of set of MSA characteristic interaction terms }\end{array}$ & {$[0.011]$} & [0.025] & [0.013] & {$[0.030]$} & [0.016] \\
\hline
\end{tabular}

Notes: All columns report OLS linear probability model estimates. Data are resume-level submissions matched to callbacks from employers to request an interview. The baseline controls included are the following: indicator variables for Associate degree, Bachelor's Degree, High quality resume, Female gender, and three job categories. In Panel C, MSA characteristics include population, GDP, average income, fraction of population with Bachelor's degree, fraction of employed in "information industries", and fraction of population non-white. Standard errors, adjusted to allow for an arbitrary variance-covariance matrix for each employment advertisement, are in parentheses and p-values are in brackets. 


\section{Table 8}

Heterogeneity in the Effect of Unemployment Duration: Resume Characteristics

\begin{tabular}{|c|c|c|c|c|c|c|c|}
\hline \multicolumn{8}{|c|}{ Dependent variable: Received callback for interview } \\
\hline & $\begin{array}{c}\text { Full } \\
\text { Sample }\end{array}$ & $\begin{array}{l}\text { Men } \\
\text { Only }\end{array}$ & $\begin{array}{c}\text { Women } \\
\text { Only }\end{array}$ & $\begin{array}{c}\text { College } \\
\text { Degree } \\
\text { Only } \\
\end{array}$ & $\begin{array}{c}\text { Non- } \\
\text { College } \\
\text { Only } \\
\end{array}$ & $\begin{array}{c}\text { High } \\
\text { Quality } \\
\text { Only } \\
\end{array}$ & $\begin{array}{c}\text { Low } \\
\text { Quality } \\
\text { Only } \\
\end{array}$ \\
\hline & $(1)$ & $(2)$ & (3) & $(4)$ & (5) & $(6)$ & $(7)$ \\
\hline \multirow[t]{3}{*}{$\log (d=$ Months unemployed $)$} & -0.011 & -0.006 & -0.014 & -0.010 & -0.011 & -0.013 & -0.009 \\
\hline & $(0.003)$ & $(0.005)$ & $(0.003)$ & $(0.005)$ & $(0.004)$ & $(0.004)$ & $(0.004)$ \\
\hline & {$[0.000]$} & [0.276] & {$[0.000]$} & {$[0.031]$} & [0.005] & {$[0.003]$} & [0.024] \\
\hline \multirow[t]{3}{*}{$\mathbf{1}\{$ Employed $\}$} & -0.020 & 0.003 & -0.032 & -0.021 & -0.017 & -0.022 & -0.018 \\
\hline & $(0.010)$ & $(0.016)$ & $(0.011)$ & $(0.016)$ & $(0.012)$ & $(0.014)$ & $(0.013)$ \\
\hline & {$[0.040]$} & [0.850] & [0.003] & {$[0.174]$} & {$[0.151]$} & {$[0.115]$} & [0.164] \\
\hline $\log (d)$ equal across cols. [p-val] & & \multicolumn{2}{|c|}{$[0.178]$} & \multicolumn{2}{|c|}{$[0.982]$} & \multicolumn{2}{|c|}{$[0.504]$} \\
\hline Average callback rate in sample & 0.047 & 0.057 & 0.041 & 0.048 & 0.047 & 0.050 & 0.044 \\
\hline $\mathrm{N}$ & 12054 & 4380 & 7674 & 4653 & 7401 & 6049 & 6005 \\
\hline $\mathrm{R}^{2}$ & 0.038 & 0.043 & 0.046 & 0.045 & 0.050 & 0.045 & 0.044 \\
\hline MSA fixed effects & $\mathrm{X}$ & $\mathrm{X}$ & $\mathrm{X}$ & $\mathrm{X}$ & $\mathrm{X}$ & $\mathrm{X}$ & $\mathrm{X}$ \\
\hline Baseline controls & $\mathrm{X}$ & $\mathrm{X}$ & $\mathrm{X}$ & $\mathrm{X}$ & $\mathrm{X}$ & $\mathrm{X}$ & $\mathrm{X}$ \\
\hline
\end{tabular}

Notes: All columns report OLS linear probability model estimates. Data are resume-level submissions matched to callbacks from employers to request an interview. The controls included are the following: indicator variables for Associate degree, Bachelor's Degree, High quality resume, Female gender, and three job categories. Standard errors, adjusted to allow for an arbitrary variance-covariance matrix for each employment advertisement, are in parentheses and pvalues are in hrarkets 
Table 9

Heterogeneity in the Effect of Unemployment Duration: Employer and Job Characteristics

\begin{tabular}{|c|c|c|c|c|c|c|c|c|c|c|c|}
\hline \multicolumn{11}{|c|}{ Dependent variable: Received callback for interview } & \\
\hline & & $\begin{array}{l}\text { Admin / } \\
\text { Clerical }\end{array}$ & $\begin{array}{c}\text { Customer } \\
\text { Service }\end{array}$ & Sales & $\begin{array}{c}\text { Jobs in } \\
\text { Construct. or } \\
\text { Manufact. }\end{array}$ & $\begin{array}{l}\text { Jobs in } \\
\text { Service }\end{array}$ & $\begin{array}{l}\text { Jobs in } \\
\text { Wholesale } \\
\text { Trade or }\end{array}$ & \multicolumn{2}{|c|}{$\begin{array}{l}\text { Job Posting } \\
\text { Mentions that } \\
\text { Experience is } \\
\text { Required }\end{array}$} & \multicolumn{2}{|c|}{$\begin{array}{l}\text { Job Posting } \\
\text { Mentions Equal } \\
\text { Opportunity } \\
\text { Employer }\end{array}$} \\
\hline & & Jobs & Jobs & Jobs & Sectors & Sectors & Retail Trade & Yes & No & Yes & No \\
\hline & (1) & $(2)$ & (3) & $(4)$ & $(5)$ & $(6)$ & (7) & (8) & (9) & (10) & (11) \\
\hline $\log (d=$ Months unemployed $)$ & {$[0.000]$} & [0.007] & [0.464] & {$[0.005]$} & {$[0.001]$} & [0.933] & [0.004] & {$[0.001]$} & {$[0.046]$} & {$[0.001]$} & [0.194] \\
\hline \multirow[t]{3}{*}{$\mathbf{1}\{$ Employed $\}$} & -0.020 & -0.016 & 0.001 & -0.036 & -0.043 & 0.004 & -0.054 & -0.040 & -0.013 & -0.016 & -0.024 \\
\hline & $(0.010)$ & $(0.011)$ & $(0.014)$ & $(0.019)$ & $(0.023)$ & $(0.012)$ & $(0.027)$ & $(0.018)$ & $(0.012)$ & $(0.010)$ & $(0.021)$ \\
\hline & {$[0.040]$} & [0.163] & [0.952] & {$[0.060]$} & [0.059] & [0.712] & {$[0.044]$} & [0.021] & {$[0.278]$} & {$[0.118]$} & [0.244] \\
\hline $\log (d)$ equal across cols. [p-val] & & \multicolumn{3}{|c|}{$[0.185]$} & \multicolumn{3}{|c|}{$[0.017]$} & \multicolumn{2}{|c|}{$[0.112]$} & \multicolumn{2}{|c|}{ [0.849] } \\
\hline MSA fixed effects & $\mathrm{X}$ & $\mathrm{X}$ & $\mathrm{X}$ & $\mathrm{X}$ & $\mathrm{X}$ & $\mathrm{X}$ & $\mathrm{X}$ & $\mathrm{X}$ & $\mathrm{X}$ & $\mathrm{X}$ & $\mathrm{X}$ \\
\hline Baseline controls & $\mathrm{X}$ & $\mathrm{X}$ & $\mathrm{X}$ & $\mathrm{X}$ & $\mathrm{X}$ & $\mathrm{X}$ & $\mathrm{X}$ & $\mathrm{X}$ & $\mathrm{X}$ & $\mathrm{X}$ & $\mathrm{X}$ \\
\hline
\end{tabular}

Notes: All columns report OLS linear probability model estimates. Data are resume-level submissions matched to callbacks from employers to request an interview. The controls included are the following: indicator variables for Associate degree, Bachelor's Degree, High quality resume, Female gender, and three job categories.

The observations do not add up to 12054 across the groups of columns in columns (5) through (11) because of missing or incomplete data in the job posting.

Standard errors, adjusted to allow for an arbitrary variance-covariance matrix for each employment advertisement, are in parentheses and p-values are in brackets. 


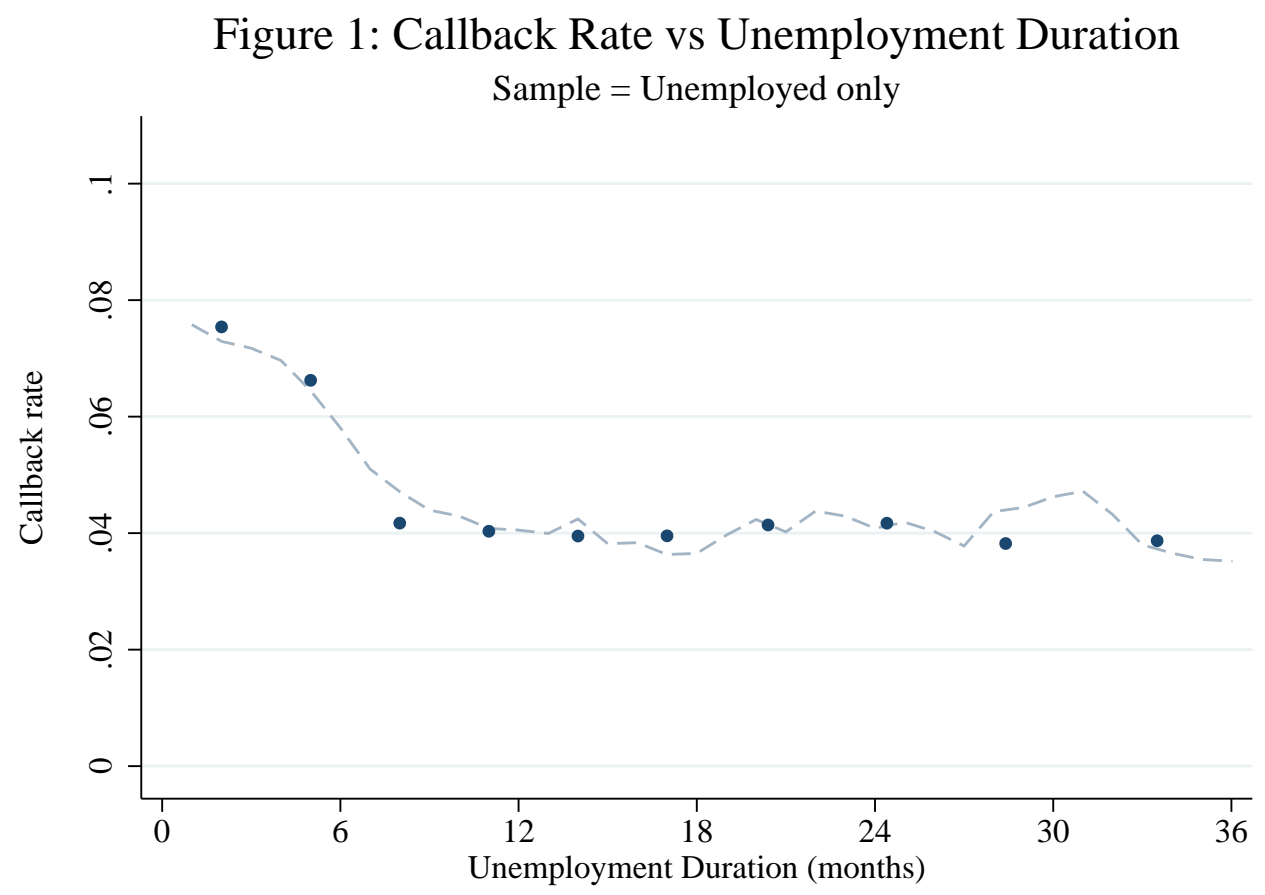

Figure 2: (Relative) Callback Rate vs Unemployment Duration

Sample = Unemployed only

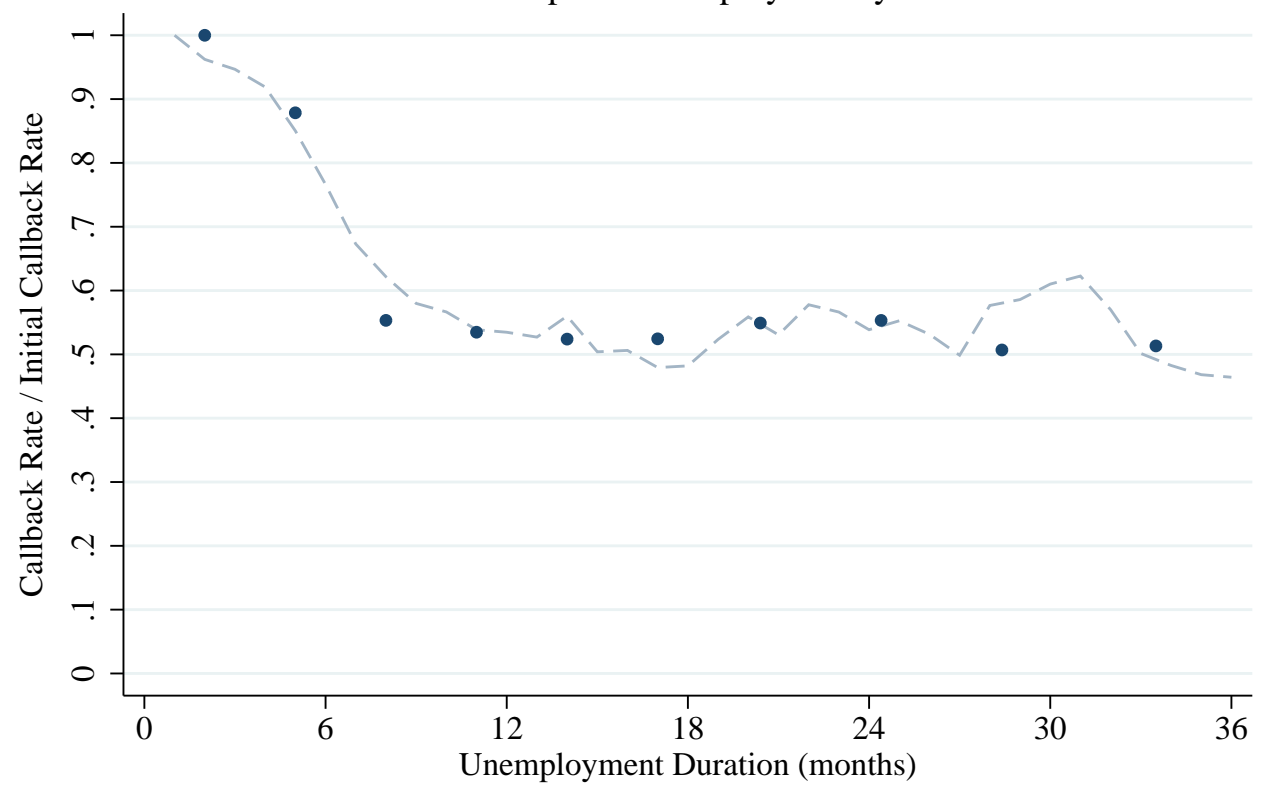

Notes: These figures are generated by computing the average callback rate for each 3-4 month bin in the range $[1,36]$. Figure 1 reports the average callback rate in each bin, while Figure 2 divides the average callback rate by the average callback rate in the first (lowest) unemployment duration bin $[1,3]$. The lines show the 5-month moving averages computed at each month. 


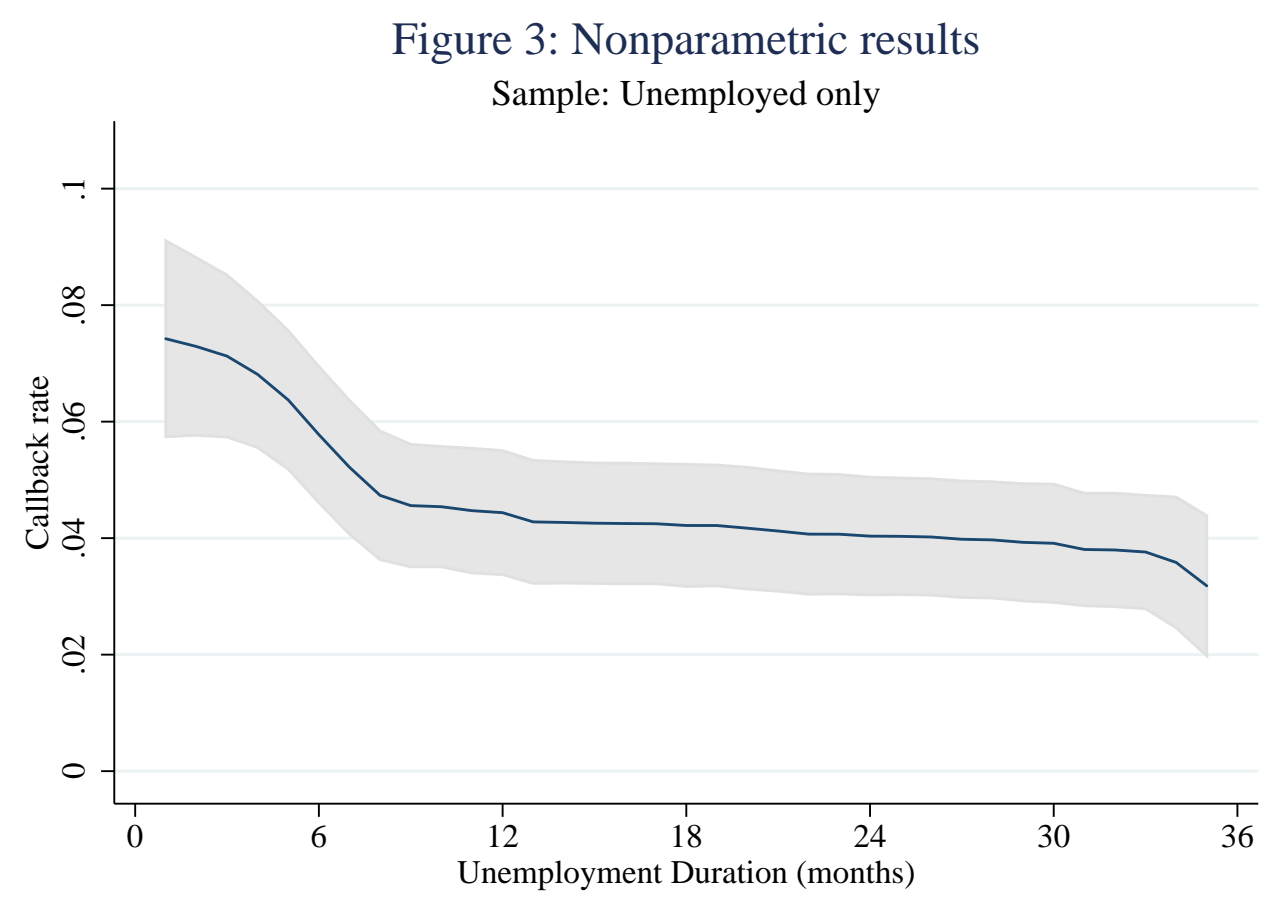

Notes: This figure is generated by estimating a local linear regression on the experimental sample, limited to the sub-sample of the unemployed. The nonparametric regression results are constrained to be monotonic following the rearrangement procedure of Chernozhukov et al. (2009). The confidence intervals are bootstrapped $95 \%$ uniform confidence intervals based on 1,000 replications. 
Figure 4: Callback Rate by Unemployment Rate

Sample = Unemployed only

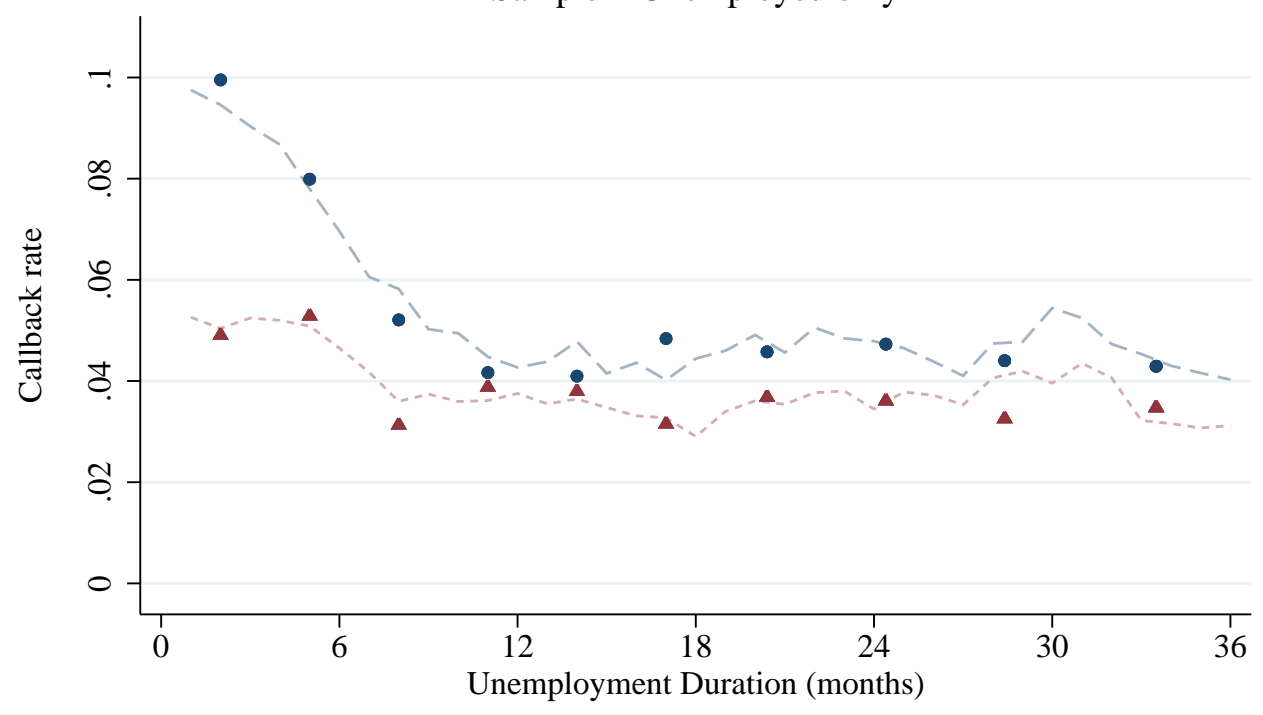

^ High unemployment rate - Low unemployment rate

Figure 5: (Relative) Callback Rate by Unemployment Rate

Sample $=$ Unemployed only

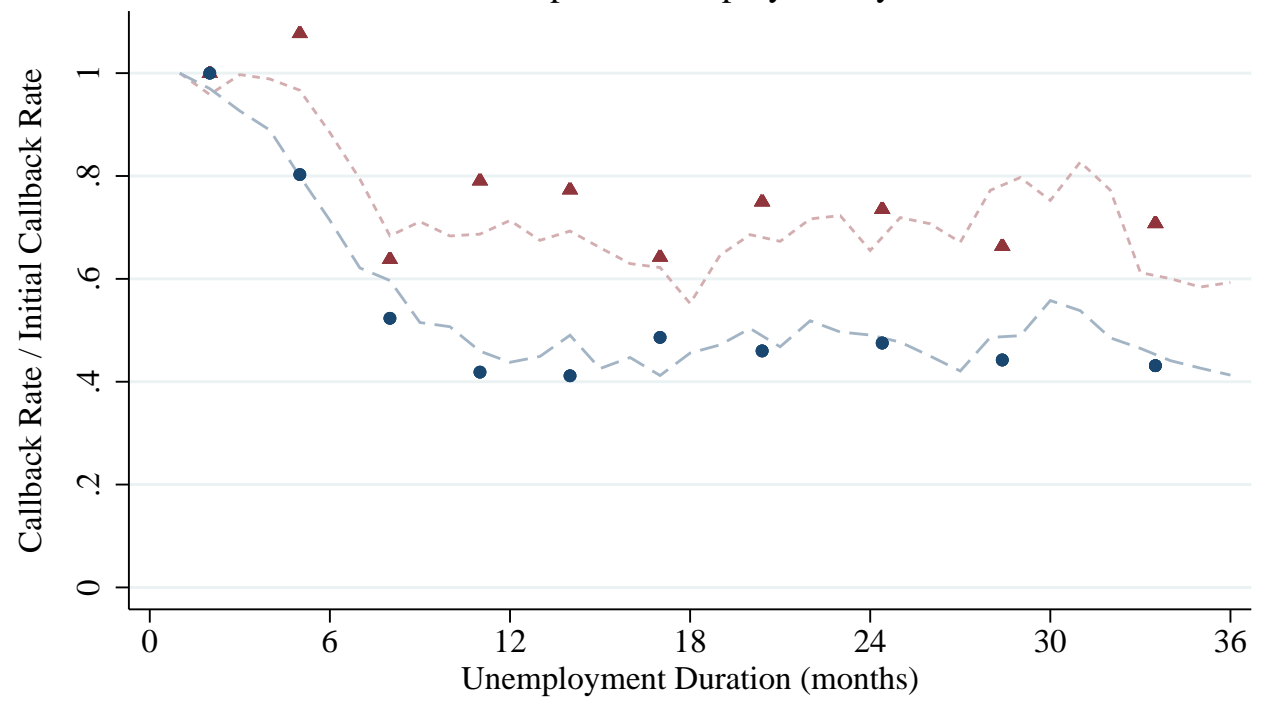

^ High unemployment rate - Low unemployment rate

Notes: These figures are generated by computing the average callback rate for each $3-4$ month bin in the range $[1,36]$ for two sub-samples of the experimental data: data from cities with low unemployment rates $(u<8.8 \%)$, and cities with high unemployment rates. Figure 4 reports the average callback rate in each bin for each sub-sample, while Figure 5 divides the average callback rate by the average callback rate in the first (lowest) unemployment duration bin $[1,3]$. The lines show the 5-month moving averages computed at each month. 

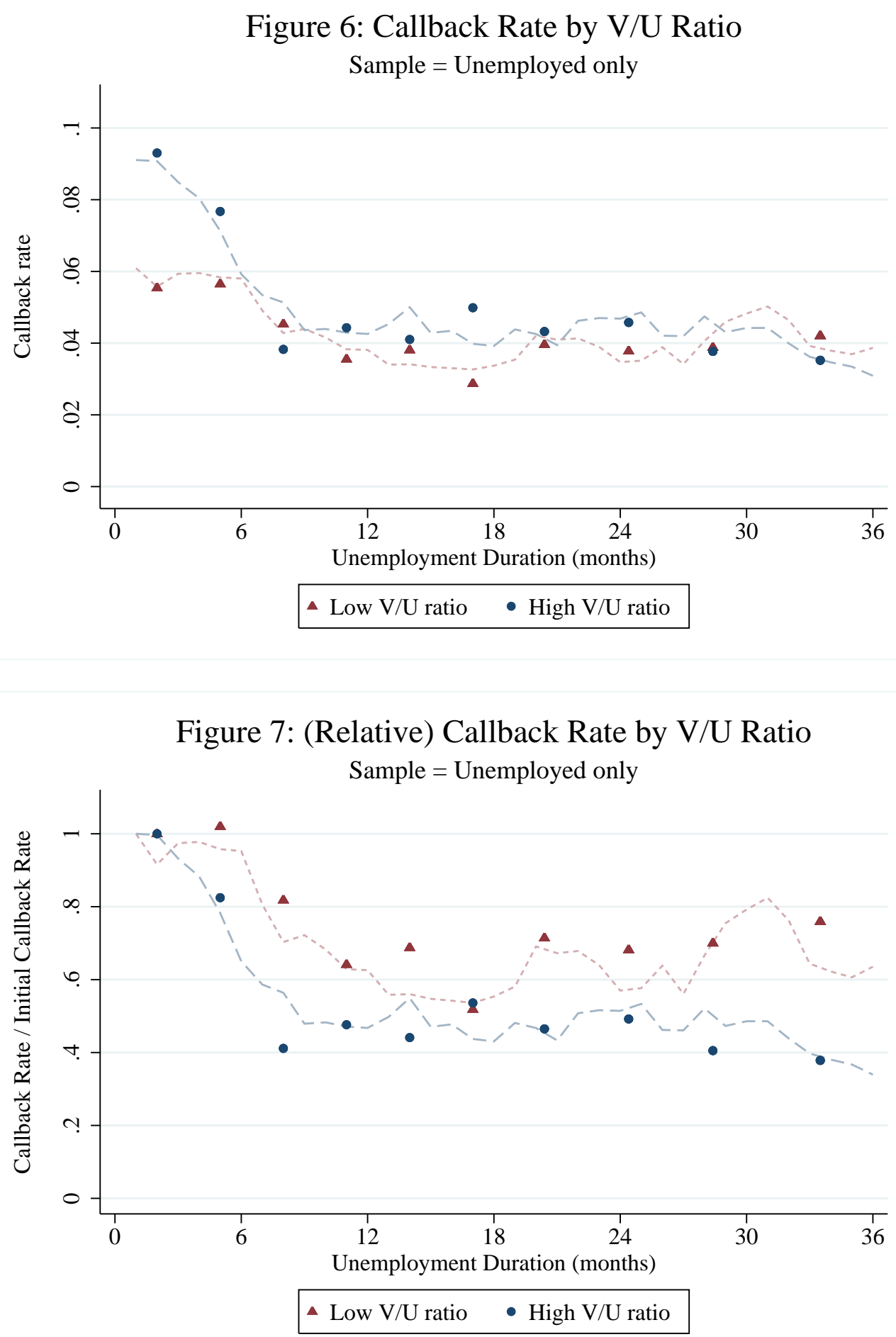

Notes: These figures are generated by computing the average callback rate for each 3-4 month bin in the range $[1,36]$ for two sub-samples of the experimental data: data from cities with high vacancy-to-unemployment ratios $(V / U>3.25)$, and cities with low $V / U$ ratios. Figure 6 reports the average callback rate in each bin for each sub-sample, while Figure 7 divides the average callback rate by the average callback rate in the first (lowest) unemployment duration bin [1,3]. The lines show the 5-month moving averages computed at each month. 


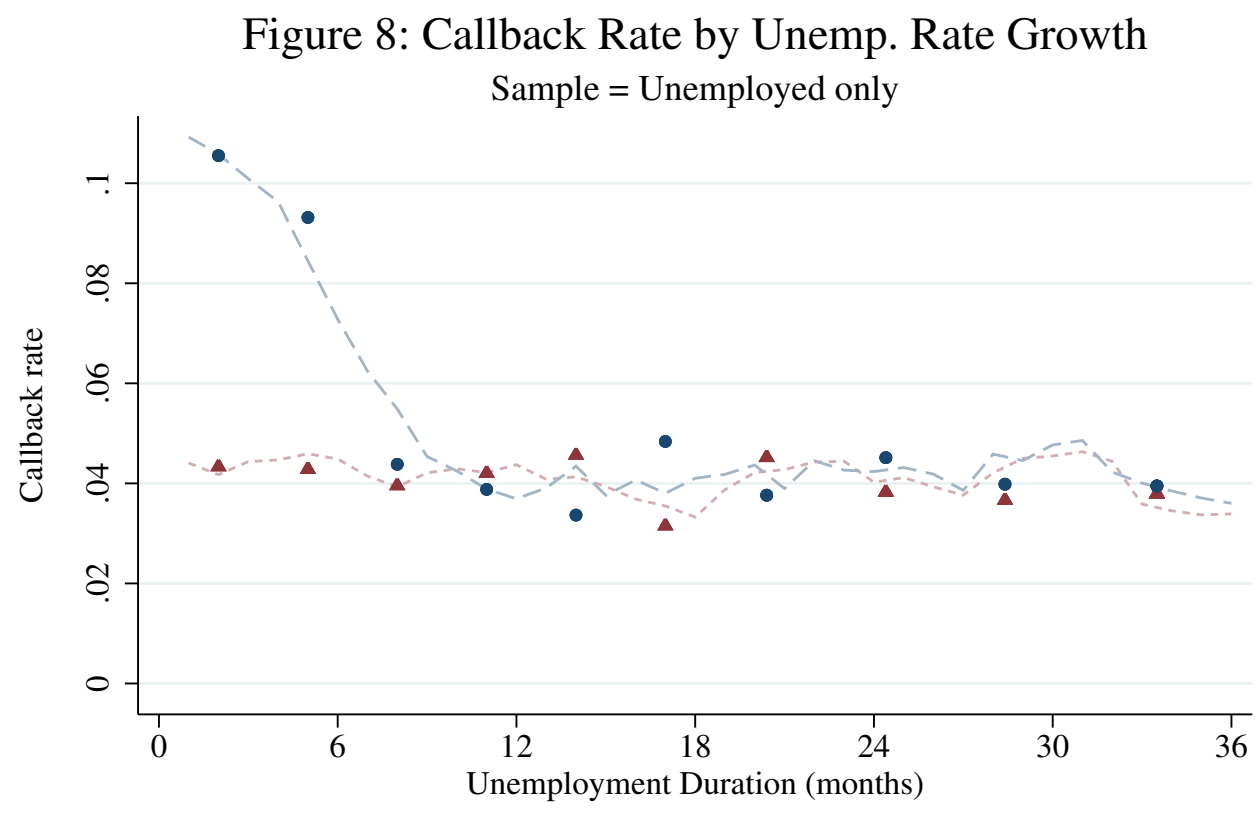

- High unemp. rate growth, '08-'11 • Low unemp. rate growth, '08-'11

Figure 9: (Relative) Callback Rate by Unemp. Rate Growth Sample $=$ Unemployed only

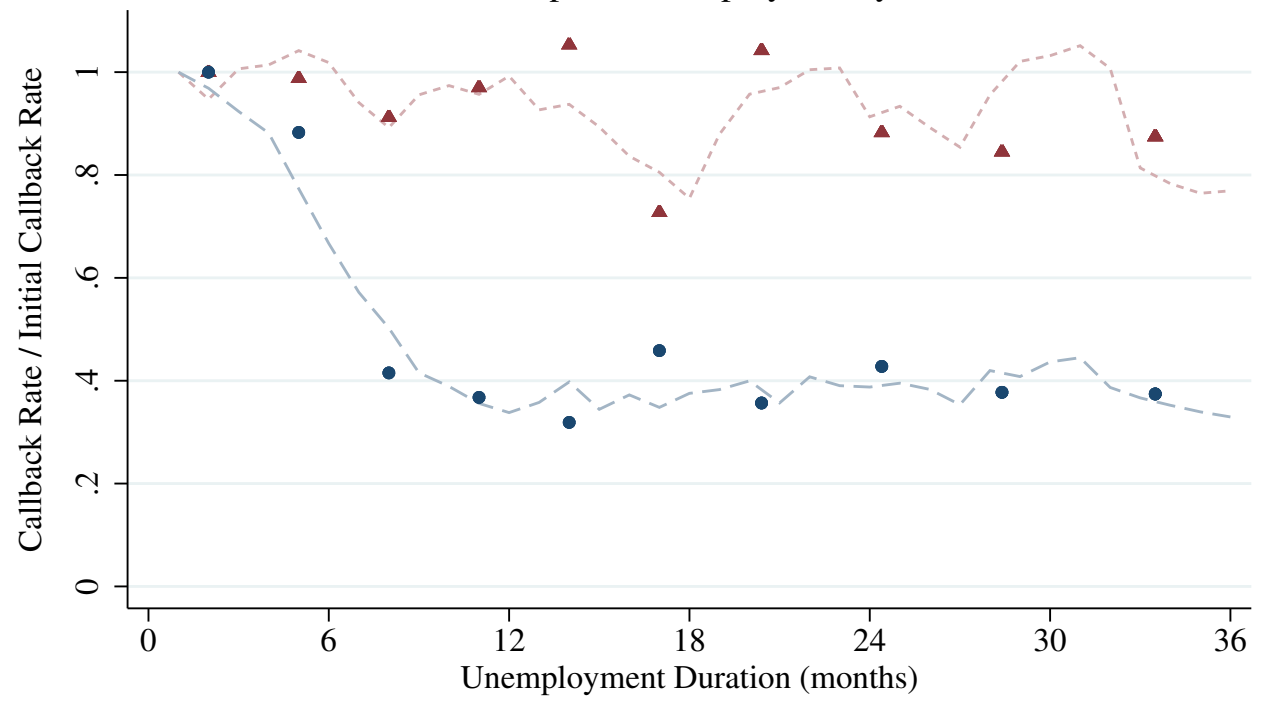

• High unemp. rate growth, '08-'11 • Low unemp. rate growth, '08-'11

Notes: These figures are generated by computing the average callback rate for each two-month bin in the range $[1,36]$ for two sub-samples of the experimental data: data from cities with low unemployment rate growth (less than 3.6 percentage points between 2008 and 2011), and cities with high unemployment rate growth. Figure 8 reports the average callback rate in each bin for each sub-sample, while Figure 9 divides the average callback rate by the average callback rate in the first (lowest) unemployment duration bin $[1,3]$. The lines show the 5-month moving averages computed at each month. 


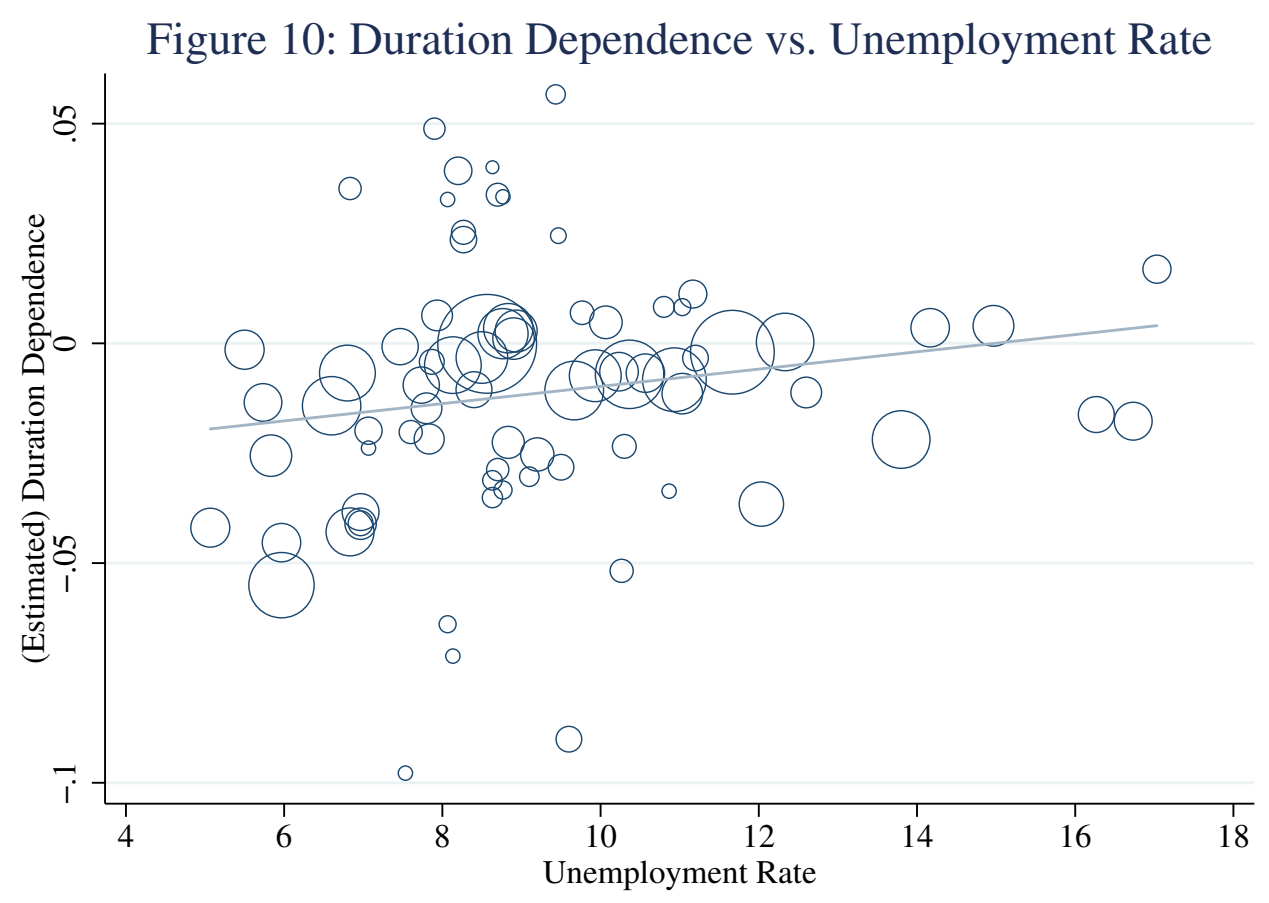

Notes: This figure shows the correlation between the MSA-specific estimated coefficient on unemployment duration (the duration dependence coefficient) and the MSA unemployment rate at the start of the experiment (July 2011). The solid line is the weighted OLS regression line using the number of observations in the MSA for the weights. The size of the circles are proportional to these weights. 


\section{Appendix A: Proof of Proposition 2 and Composition Bias}

\section{Proof of Proposition 2}

Recall that $r(d ; x)$ and $\theta(d ; x)$ are defined as follows:

$$
\begin{aligned}
r(d ; x) & =\frac{h(d ; x)}{h(0 ; x)} \\
\theta(d ; x) & =\frac{\pi(d ; x)}{1-\pi(d ; x)}
\end{aligned}
$$

From the expressions above, it is clear that $r(\pi(d ; x) ; x)$ increases in $\pi(d ; x)$. Therefore, to establish the proposition, we need to establish the relationship between $\pi(d ; x)$ and $x$. It is sufficient to sign the relationship between $\theta(d, x)$ and $x$.

First, note that $\theta(0, x)=\theta\left(0, x^{\prime}\right)$ for $x \neq x^{\prime}$. This follows from the assumption that $\pi(0 ; x)=\pi_{0}$. Next, from definition of $\theta(d, x)$, it is simple to show that

$$
\frac{\partial \theta(d ; x)}{\partial d}=-m(x) \times \theta(d ; x) \times\left(l_{h}(\pi(d ; x))-l_{l}(\pi(d ; x))\right)
$$

Since $m^{\prime}(x)>0$ and $l_{h}\left(\pi_{0}\right)>l_{l}\left(\pi_{0}\right),\left|\frac{\partial \theta\left(0 ; x^{\prime}\right)}{\partial d}\right|>\left|\frac{\partial \theta(0 ; x)}{\partial d}\right|$. This establishes that for small $\varepsilon>0, x^{\prime}>x$ $\Rightarrow \theta(\varepsilon ; x)>\theta\left(\varepsilon ; x^{\prime}\right)$. In other words, the share of high types is initially lower in tighter markets. This is intuitive as high types get selected out of unemployment relatively faster.

To complete the proof, we need to show that $\forall d>0, x^{\prime}>x \Rightarrow \theta(d ; x)>\theta\left(d ; x^{\prime}\right)$. We will proceed by contradiction. Suppose that this were not true. Then since $\theta\left(d ; x^{\prime}\right)$ initially lies below $\theta(d ; x), \exists d^{*}>0$ such that $\theta\left(d^{*} ; x\right)=\theta\left(d^{*} ; x^{\prime}\right)$ and $\theta\left(d^{*}+\varepsilon ; x\right)<\theta\left(d^{*}+\varepsilon ; x^{\prime}\right)$. By the definition of $d^{*},\left|\frac{\partial \theta\left(d^{*} ; x^{\prime}\right)}{\partial d}\right|>\left|\frac{\partial \theta\left(d^{*} ; x\right)}{\partial d}\right|$. However, this would imply that $\theta\left(d^{*}+\varepsilon ; x\right)>\theta\left(d^{*}+\varepsilon ; x^{\prime}\right)$, a contradiction. Thus, it follows that a single crossing property has to hold for $\theta(d ; x)$ and $\theta\left(d ; x^{\prime}\right)$. And, since $\theta(0 ; x)=\theta\left(0 ; x^{\prime}\right)$, we have that $\theta(d ; x)>\theta\left(d ; x^{\prime}\right)$ and consequently $r(d ; x)>r\left(d ; x^{\prime}\right)$ for all $d>0$.

\section{Composition Bias}

Recall equation (10)

$$
c(d) \equiv \int c(\phi) \frac{d \Phi(\phi \mid d)}{d \phi} d \phi
$$

Differentiating with respect to $d$ yields:

$$
c^{\prime}(d) \equiv \int c(\phi) \frac{d^{2} \Phi(\phi \mid d)}{d \phi d d} d \phi
$$

Note that

$$
\Phi(\phi \mid d)=\pi(d) \Phi_{h}(\phi \mid d)+(1-\pi(d)) \Phi_{l}(\phi \mid d)
$$

where $\pi(d)=\int \pi(d, \phi) d \Phi(\phi \mid d)$. Hence,

$$
\frac{d \Phi(\phi \mid d)}{d \phi}=\pi(d) \frac{d \Phi_{h}(\phi)}{d \phi}+(1-\pi(d)) \frac{d \Phi_{l}(\phi)}{d \phi}
$$

Thus,

$$
\frac{d^{2} \Phi(\phi \mid d)}{d \phi d d}=\frac{d \pi(d)}{d d}\left(\frac{d \Phi_{h}(\phi)}{d \phi}-\frac{d \Phi_{l}(\phi)}{d \phi}\right)
$$


Plugging this back into (16), we get

$$
\begin{aligned}
& c^{\prime}(d)=\frac{d \pi(d)}{d d}\left[\int c(\phi) d \Phi_{h}(\phi)-\int c(\phi) d \Phi_{l}(\phi)\right] \\
& c^{\prime}(d)=\frac{d \pi(d)}{d d}\left[E_{h}[c(\phi)]-E_{l}[c(\phi)]\right]
\end{aligned}
$$

By the proposition above, $\frac{d \pi(d)}{d d}<0$. By first-order stochastic dominance and the fact that $c^{\prime}(\phi)>0$, the expression inside the brackets is positive. This establishes that $c^{\prime}(d)<0$.

\section{Appendix B: Properties of Incomplete and Complete Spells}

We distinguish between two duration concepts - "incomplete" and "completed spells". That is, we define the random variable $D$ as the length of an unemployed worker's incomplete spell. This random variable is to be distinguished from $\mathrm{S}$, the length of a completed spell of unemployment. Clearly, realizations $s$ and $d$ of these random variables satisfy $s \geq d$. Denote the conditional distribution and density functions of completed spells at time $t$ as $G_{y}^{S}(S)$ and $g_{y}^{S}(S)$. For incomplete spells, we will use the notation $G_{y}^{D}(D)$ and $g_{y}^{D}(D)$.

There is a connection between the distribution of completed and ongoing spells in the steady state. Salant (1977) demonstrates that in the steady-state, the density of on-going spells is connected to the distribution of completed spells as follows:

$$
g_{y}^{D}(\tau)=\frac{1-G_{y}^{S}(\tau)}{E[S]} \text { for } \tau \geq 0
$$

We can also define the escape rate conditional on spell length $\tau$ as the rate at which individuals leave the population of unemployed at $\tau$. This can be expressed as a function of the density and distribution of completed spells:

$$
h_{y}(\tau)=\frac{g_{y}^{S}(\tau)}{1-G_{y}^{S}(\tau)}=-\frac{d}{d S} \ln \left[\int_{\tau}^{\infty} g_{y}^{S}(\mu) d \mu\right]
$$

Rewriting this, we get

$$
\begin{aligned}
\frac{d}{d \tau} \ln \left[1-G_{y}^{S}(\tau)\right]+h_{y}(\tau) & =0 \\
\frac{d}{d \tau}\left[1-G_{y}^{S}(\tau)\right]+\left(1-G_{y}^{S}(\tau)\right) h_{y}(\tau) & =0
\end{aligned}
$$

This is a first-order differential equation with a variable coefficient. The general solution of this equation, the distribution function for completed spells, satisfies:

$$
\operatorname{Pr}(S>\tau)=1-G_{y}^{S}(\tau)=\exp \left(-\int_{0}^{\tau} h_{y}(\mu) d \mu\right)
$$

This is simply the probability that the individual has not been hired up to $S$. And, this implies the following density:

$$
g_{y}^{S}(\tau)=h_{y}(\tau) \exp \left(-\int_{0}^{\tau} h_{y}(\mu) d \mu\right)
$$

\section{Appendix C: Model of Employer-Screening}

In this section, we show that a model of search frictions with employer screening will satisfy the requirements of the mechanical model of Section 2. We assume that (i) firms open vacancies subject to a zero-profit 
condition; (ii) workers and firms meet according to a reduced-form meeting function; (iii) upon meeting a worker, firms receive a signal $\phi$ on the worker's productivity $(y=h$ or $l$, with $h>l$ ) and decide whether or not to interview the worker at a cost; (iv) some applicants are called back for an interview (a costly screen) where the firm obtains additional information in the form of signal z. If the expected profit of firm is positive, then the individual is offered the jobs. The expected profit depends on the wage and we need to make an assumption on wage setting. In the simplest version of the model, we assume that wages offered by all firms will equal the outside opportunity of workers which is denoted by b. As we show below, this model maps into the mechanical structure discussed in Section 2 since (i) a matching function of the required type is assumed to govern the rate at which firms and workers meet; (ii) high type applicants are more likely to be hired conditional on matching than low type applicants; and (iii) hiring rates conditional on matching decline with $\pi(d ; \phi)$.

While we discuss the model for the simplest possible form of wage setting with $w=b$, it is also possible to allow for more general forms of wage setting. For instance, we could assume that wages are set to be equal to $\mathrm{b}$ plus a fixed share in the expected surplus from a given job. For instance, we might expect that $w=b+\lambda(E[y \mid \pi(d ; \phi), z]-b)$ where $\lambda \in[0,1]$. In this case, firms would invite fewer individuals for interviews, since the expected surplus $(1-\lambda)(E[y \mid \pi(d ; \phi), z]-b)$ going to the firm would be smaller and thus the interview costs would be covered in fewer cases. Therefore a model with surplus sharing will have inefficiently low interview rates. Notwithstanding the fact that the welfare implications would differ under this form of wage setting, it is possible to show that the requirements (ii) and (iii) on hiring rates conditional on matching will still be satisfied and that therefore the predictions of the mechanical model still apply.

\section{Model Setup}

\section{Population Dynamics and Workers}

We maintain the assumptions on matching and on the life-cycle of individuals that we have described in Section 2.1. In addition, we assume that workers receive benefits $b$ when unemployed and we assume that $l<b<h$. These benefits are constant with respect to productivity and they determine the outside option of unemployed workers. ${ }^{28},{ }^{29}$

\section{Firms / Vacancies}

There is no fixed cost to opening a vacancy, but each period that a vacancy is open a flow cost $c$ needs to be paid. There is free-entry. ${ }^{30}$ Filling or keeping open the current vacancy does not affect the ability to open future vacancies, nor does it have any impact on the costs and benefits associated with any future vacancies. Thus, firms fill vacancies as soon as they find a match such that the expected profit of the vacancy is positive. Firms care only about the productive type of a worker.

We assume that firms offer a wage of $b$. Offering $b$ represents a Nash equilibrium because we assume that applicants accept job offers with a pay-off equal to the expected pay-off from remaining unemployed. If all firms offer $b$, then the pay-off from remaining unemployed is also $b$ and workers accept these job offers. Further, no firm has an incentive to make a higher offer.

Once a vacancy is filled, it generates an output stream $y$ until the individual retires. Since the wage $b$ exceeds the productivity of the less able type, firms have an interest in hiring only high productivity workers. ${ }^{31}$ We assume that firms hold rational expectations. Thus, firms' beliefs about the probability that

\footnotetext{
${ }^{28}$ Type fully predicts productivity in this model. Another formulation would allow type to determine productivity probabilistically. See Gonzales and Shi (2009) for a learning model.

${ }^{29}$ Krueger and Mueller (2011) find empirical support for the observation that the reservation wage does not vary with unemployment durations. See also Kasper (1967) as well as Feldstein and Poterba (1984).

${ }^{30}$ The matching technology generates a rate of matching for a given vacancy that is independent of the number of vacancies a firm opens. Further, the flow cost of maintaining a vacancy is likewise independent of the number of vacancies a firm opens. These constant returns to scale assumptions imply that the size of firms is indeterminate. We will therefore treat each vacancy as a firm in its own right.

${ }^{31}$ We are assuming here that firms hold onto non-profitable workers $(b>l)$ forever. In other words, ex ante profits are driven to 0 in eqm but ex post there will be workers on which firms make losses. The assumption that relationships are maintained regardless of their productivity is clearly ad-hoc. We have in mind that firms incur losses on workers that are not productive
} 
a worker of duration $d$ and signals $\phi$ and $z$ is of high type will equal the distribution that arises in equilibrium.

\section{The Signals}

We assume the same matching process as described above. Upon meeting, firms observe how long an individual has been unemployed (a draw $d$ from the random variable $D$ ). The firm also observes an additional signal $\phi$ on the productivity of the worker - which we interpret to reflect the unobserved characteristics of the $\mathrm{CV}$ as described in Section 2. Given this additional signal, the firm can decide whether or not to interview the worker at a fixed cost $\xi$. If the firm chooses to interview the worker, it then receives another signal $z$ on the worker type $y$. Without loss of generality, we assume that this signal represents new information about the worker type that is orthogonal to the prior $\pi(d, \phi)$ that firms hold about worker productivity when they make callback decisions. For simplicity, we assume that distribution of the scalar signal only depends on the type $y$ and write the distribution function for $z$ conditional on productivity $y$ as $F_{y}^{z}($.$) . Assume further that$ $F_{l}^{z}($.$) and F_{h}^{z}($.$) satisfy a monotone likelihood ratio property. This captures the idea that z$ is informative about the underlying type.

Assumption 4 [Monotone Likelihood Ratio] $F_{l}^{z}($.$) and F_{h}^{z}($.$) satisfy the MLR property so that \frac{f_{h}^{z}(k)}{f_{l}^{z}(k)}(\text { strictly })^{32}$ increases in $k^{33}$

Implied in this assumption is first-order stochastic dominance $\left(F_{l}^{z}(k)-F_{h}^{z}(k)>0\right.$ for all $\left.k\right)$. Continuous distributions satisfying MLR include the exponential family and the normal distribution. This assumption implies that firms pursue a "reservation signal policy" for both callbacks and hiring decisions. When a firm has observed $(Z=z, \phi, D=d)$, the firm decides whether or not to hire the worker.

\section{Equilibrium}

We begin by defining an equilibrium and the pay-off functions for firms in this economy. Denote by $J_{u}$ the value of an open vacancy, by $J_{m}$ the value of matching to an applicant before deciding on whether to interview this applicant and by $J_{I}$ the value of having interviewed an applicant with duration $d$ and signal $z$. Equation (20) says that the return on an unfilled vacancy depends on the flow cost of each vacancy, market tightness $x$, and the joint distribution of duration and signals $G^{D}(d, \phi)$ in the population. At rate $m_{v}(x)$, a vacancy meets with a worker, who is drawn from the joint distribution of incomplete spells (see Appendix B) and signals $\phi: G^{D}(d, \phi)$ :

$$
r J_{u}=-c+m_{v}(x) \int_{d} \int_{\phi} J_{m}(d, \phi) d G^{D}(d, \phi)
$$

The value of a match depends on the signal $\phi$ drawn for this match and the duration $d$ of the applicant. This value equals the maximum of the value of keeping the vacancy open and the expected value of interviewing the worker net of interview cost $\xi^{34}$ :

$$
J_{m}(d, \phi)=\max \left\{J_{u}, \int_{z} J_{I}(d, z, \phi) d F(z \mid d, \phi)-\xi\right\}
$$

The distribution $F(z \mid d, \phi)$ depends only on the prior $\pi(d, \phi)$ :

$$
\begin{aligned}
F(z \mid d, \phi) & =\pi(d, \phi) F_{h}(z)+(1-\pi(d, \phi)) F_{l}(z) \\
& =F(z \mid \pi(d, \phi))
\end{aligned}
$$

and that they will therefore strive to avoid hiring low-productivity workers.

\footnotetext{
${ }^{32}$ By assuming that the likelihood ratio strictly increases, we ensure that as $z$ increases, the posterior probability of being the high type will approach 1 .

${ }^{33}$ WLOG, because we can always reassign the support of $\mathrm{z}$.

${ }^{34}$ Here we assume that to hire an applicant, an interview is always necessary. This assumption can be justified by the fact that workers in our experiment are always required to submit a CV to a vacancy and rarely are they offered a job at this stage.
} 
Upon interviewing the candidate, the firm updates its beliefs and obtains the value $J_{I}(d, z, \phi) . J_{I}(d, z, \phi)$ is the maximum of the expected present discounted value of profits from hiring this interviewee and the value of rejecting her and keeping the vacancy open. The expected flow return to a filled vacancy is the expected productivity conditional on the observed signals net of the wage $(b)$. Expected productivity depends on the prior $\pi(d)$ as well as the signals $\phi$ and the signal $z \cdot{ }^{35}$ With rate $\delta$, individuals retire and the match is consequently dissolved. Thus, the flow return from a filled vacancy is discounted using both the interest rate $r$ and the retirement rate $\delta$.

$$
\begin{aligned}
J_{I}(d, z, \phi) & =\max \left\{J_{u}, \frac{1}{r+\delta}(E[y \mid z, \pi(d, \phi)]-b)\right\} \\
& =J_{I}(z, \pi(d, \phi))
\end{aligned}
$$

The rational expectations equilibrium consists of $x=V / U$, an interview rule, a hiring rule, and a joint distribution $G^{D}(d, \phi, z, y)$ that satisfy:

1. Firms interview workers if and only if $\int_{z} J_{I}(z, \pi(d, \phi)) d F(z \mid \pi(d, \phi)) \geq \xi$.

2. Firms hire workers if and only if $E[y \mid \phi, d, z] \geq b$.

3. Given $x$ and implied $m_{v}(x)$, vacancies do not earn profits in expectation: $J_{u}=0$.

4. Beliefs about the distribution of productivity $\pi(\phi, d)$ equal the equilibrium realized distribution $\pi(\phi, d)$.

\section{Characterizing Firm's Behavior}

It is easy to show the hiring rates in this model satisfy the two requirements of the mechanical model. We will show this for a given $\phi$. These properties of the hiring rates are maintained when we aggregate across $\phi$.

1. Conditional on $\pi$, hiring rate for high types exceeds that for low types.

For a given $\pi(d, \phi)$, the interview rate is the same for high or low types. However, the expected productivity $E[y \mid \phi, d, z]=E[y \mid \pi(\phi, d), z]$ increases in z. Since $F_{h}(z)$ FOSD $F_{l}(z)$, high types are more likely to receive high signals than low types. The equilibrium condition 2 on hiring is therefore satisfied more often for high rather than low types.

2. Conditional on type, hiring rates increase in $\pi$ By FOSD, we have that $F(z \mid \pi)$ increases in $\pi$ and that $J_{I}(z, \pi)$ increases in z and $\pi$. Therefore, $\int_{z} J_{I}(z, \pi(d, \phi)) d F(z \mid \pi(d, \phi))$ increases in $\pi$. Thus, callback rates for any type of worker (high or low) increase in $\pi$, satisfying the conditions of corrolary 1 . Furthermore, we have again that $E[y \mid \pi, z]$ increases in $\pi$. Since the type-specific distribution $F_{y}(z)$ does not depend on $\pi$, hiring rates for a given type increase in $\pi$.

Thus, both conditions on hiring rates and the matching structure of the mechanical model are satisfied by this screening model. Furthermore, the condition of corollary 1 is satisfied. It follows that the model exhibits negative duration dependence and that the model implies that duration dependence worsens if markets are tighter.

\section{Appendix D: Model of Human Capital Depreciation}

An alternative interpretation of duration dependence in unemployment is that workers skills depreciate during unemployment. We present a simple model that captures this idea. Our main point is to illustrate that this model does not imply that that duration dependence interacts with market tightness. We can

\footnotetext{
${ }^{35}$ To form this expectation, firms use the joint distribution of incomplete durations, signals, and productivity at time t: $G^{D}(D, Z, y ; t)$.
} 
thus test this model based on human capital depreciation against the screening model using the interaction between market tightness and unemployment durations.

In contrast to the screening model, the idea of skill depreciation does not emphasize information problems on the part of employers about the productivity of applicants. Instead, in human capital models, information about the general skills of workers are known to employers. We therefore assume that, conditional on $\phi$, all individuals have the same market skills. Instead of introducing an additional variable, we will simply assume that $\phi$ equals the human capital / productivity of a worker. Let $\phi$ at $d=0$ be given by $\phi_{0}$ and use $\Phi$ to denote the distribution of $\phi_{0}: \phi_{0} \sim \Phi$. We assume that individual human capital depreciates exponentially at rate $\rho$ while unemployed. At $d>0$, individual human capital is given by $\phi(d)=\phi_{0} \exp (-\rho d)$.

In addition to general human capital, we assume that the match between workers and firms has a matchspecific component. That is, we assume that the output of any match is given by by $\phi+\varepsilon_{i j}$ where $\varepsilon_{i j}$ is independent of $\phi$ and drawn from distribution $F_{\varepsilon}$. The independence assumption on $\varepsilon$ captures the intuition that this component does not depend on worker or firm characteristics but is instead specific to each match.

As above, the unemployed and vacancies are matched at rate $m(x)$. Upon meeting, a firm observes $\phi$ and $d{ }^{36}$ but needs to interview a worker in order to discover the match specific component $\varepsilon$. As before, we assume that interviews are costly and for simplicity we assume that firms cannot hire a worker without interviewing her first.

The value function for an open vacancy is very similar to that of the screening model given in eq. (20) :

$$
r J_{u}=-c+m_{v}(x) \int_{d} \int_{\phi_{0}} J_{m}\left(d, \phi_{0}\right) d G^{D}\left(d, \phi_{0}\right)
$$

Upon meeting, the firm again has to choose whether to interview the worker with characteristics $\phi$ and pay the interview cost of $\xi$. The problem is similar to the one above, except that the expectation is taken over the match specific component $\varepsilon$ :

$$
J_{m}\left(d, \phi_{0}\right)=\max \left\{J_{u}, \int_{\varepsilon} J_{I}\left(\phi_{0}, d, \varepsilon\right) d F(\varepsilon)-\xi\right\}
$$

We maintain the wage setting assumption that workers are paid their outside option $b$. The value of a filled vacancy is therefore

$$
J_{I}\left(d, \phi_{0}, \varepsilon\right)=\max \left\{J_{u}, \frac{1}{r+\delta}\left(\phi_{0} \exp (-\rho d)+\varepsilon-b\right)\right\}
$$

Imposing the free entry condition, we have that a job is filled if

$$
\varepsilon \geq b-\exp (-\rho d) \phi_{0}
$$

Thus, conditional on matching and interviewing, the rate at which interviewees with $\left(\phi_{0}, d\right)$ are hired is $l\left(\phi_{0}, d\right)=1-F_{\varepsilon}\left(b-\exp (-\rho d) \phi_{0}\right)$. This rate declines in $d$. Now, since $J_{I}\left(d, \phi_{0}, \varepsilon\right)$ increases in $\phi_{0}$ and decreases in $d$, we have that the callback rate $c\left(\phi_{0}, d\right)$ increases in $\phi_{0}$ and decreases in $d$. We thus have that the hiring rate is given by $h\left(\phi_{0}, d\right)=m(x) c\left(\phi_{0}, d\right) l\left(\phi_{0}, d\right)$ and satisfies $\frac{\partial h\left(\phi_{0}, d\right)}{\partial d}<0$.

Thus, the model generates true duration dependence in hiring rates and our experiment will find true duration dependence in callback rates $c\left(\phi_{0}, d\right)$. However, consider the functions $r(d, x)=\frac{h(d, x, \phi)}{h(0, x, \phi)}$ and $r^{c}(d, x)=\frac{c(d, x, \phi)}{c(0, x, \phi)}$ that we have used to generate a testable implication for models following the structure of the mechanical model described in Section 2. For the model based on human capital depreciation, these two

\footnotetext{
${ }^{36}$ We assume that the firm knows the relationship $\phi(d)=\phi_{0} \exp (-\rho d)$ so, given $\phi$ and $d$, it can recover $\phi_{0}$. Thus, observing $\phi$ and $d$ is equivalent to observing $\phi_{0}$ and $d$. We adopt this convention when defining the value functions below.
} 
functions are:

$$
\begin{aligned}
r\left(d, x, \phi_{0}\right) & =\frac{c\left(\phi_{0}, d\right) l\left(\phi_{0}, d\right)}{c\left(\phi_{0}, 0\right) l\left(\phi_{0}, 0\right)} \\
r^{c}\left(d, x, \phi_{0}\right) & =\frac{c\left(\phi_{0}, d\right)}{c\left(\phi_{0}, 0\right)}
\end{aligned}
$$

Neither of them depend on market tightness $x$. Therefore, it is possible to distinguish the depreciation model from the screening models described above exploiting the functions $r^{c}(d, x, \phi)$. Crucial however is again that the distribution of characteristics $\phi$ is adequately controlled for - and as we argue above, this requires experimental data of the type we exploit below.

\section{Appendix E: Ranking as an Alternative Model of Employer Generated Duration Dependence}

As an alternative to screening, Blanchard and Diamond (1994) (BD) developed a model of employer driven duration dependence building on the idea of ranking. According to the ranking model, vacancies accept multiple applications over a discrete, positive duration of time and then rank all applications against each other according to their duration. The ranking hypothesis is that firms hire the applicant with the shortest duration. Naturally, this model as discussed by BD generates duration dependence.

In each period, workers are assumed to send out an application with probability $a$. BD further assume that markets are large in the sense that $U(d)$ and $V \rightarrow \infty$, where $U(d)$ is the number of unemployed with duration less than $d .^{37}$ Given this assumption, the probability that any vacancy receives an application of an individual with duration $d$ or less is equal to $1-\exp \left(-\frac{a U(d)}{V}\right)$.

Since applications are independently assigned to vacancies, this probability is also the probability that an applicant of duration $d$ will find himself applying to a vacancy for which another individual with a shorter duration also applies. The probability that an unemployed individual of duration $d$ finds a job is therefore equal to the product of the probability that he sends an application times the probability that nobody of shorter duration applies to the same vacancies. Denoting by $h_{R}(d)$ the hazard function from leaving unemployment in BD's model, we obtain ${ }^{38}$ :

$$
h_{R}(d)=a \exp \left(\frac{-a U(d)}{V}\right)
$$

In this model, the probability a worker matches with a firm, $m_{u}(x)=a$, does not depend on market tightness. ${ }^{39}$ Conditional on a worker matching with a firm, the probability he gets hired is $l(d)=\exp \left(\frac{-a U(d)}{V}\right)$. Thus, the job finding rate $h_{R}(d)$ has a similar structure to the mechanical model above; namely the match probability times the hiring probability.

Since $U(d)$ is by construction an increasing function, we have that $\frac{\partial h_{R}(d)}{\partial d}<0$. Thus, the ranking and the screening models both generate true duration dependence and it is not possible to distinguish between them on the basis of this finding. However, as we will argue below, the models differ fundamentally in how labor market conditions affect duration dependence - screening predicts that tighter markets lead to more duration dependence, whereas ranking predicts that tighter markets lead to less duration dependence.

\footnotetext{
${ }^{37}$ We do not fully develop the BD model here, but refer the reader to the original work.

${ }^{38}$ This is equation (15) in $\mathrm{BD}$.

${ }^{39}$ Blanchard and Diamond note that in a more realistic model, $a$ would depend on the state of labour market. They do not consider this possibility.
} 


\section{Interaction Between Duration Dependence and Market Conditions}

Consider the function $r_{R}(d)=\frac{h_{R}(d)}{h_{R}(0)}$ obtained from the ranking model:

$$
r_{R}(d)=\exp \left(-a \frac{U(d)-U(0)}{V}\right)=\exp \left(-a \frac{U(d)}{V}\right)
$$

where we use the fact that in continuous time there is no mass of individuals with durations less than or equal to $d=0$. Thus, we see directly how duration dependence as measured by $r_{R}(d)$ depends on a particular measure of market conditions: the ratio of the currently unemployed with durations shorter than $d$ to the total number of vacancies. If market conditions tighten in the sense that this ratio declines, then $r_{R}(d)$ increases. ${ }^{40}$ Thus, in this sense tighter labor markets are associated with less duration dependence.

Therefore, we can distinguish the screening, human capital depreciation and the ranking model by either (i) examining whether durations vary with current or with past market conditions or (ii) by examining whether duration dependence is more or less negative in permanently tighter labor markets. It is this second implication that we use to motivate the design and implementation of our resume audit study.

\section{Appendix F: Measuring Salience of Resume Characteristics Using Web-Based Survey of MBA Students}

Our experiment assumes that employers are aware of (and can therefore respond to) information about a job applicant's unemployment spell. To test this assumption, we designed and conducted a web-based survey. We recruited 365 first-year MBA students at the University of Chicago Booth School of Business by e-mail on April 9, 2012, and the web-based survey was successfully completed by 90 MBA students. ${ }^{41}$ The students did not receive any compensation for participation, and they took roughly 5-10 minutes on average to complete the survey. ${ }^{42}$

The survey took place in three stages. In the first stage (Appendix Figure A1), respondents were asked to read a hypothetical job posting and consider two resumes for the job opening. The job posting was chosen at random from one of three candidate job postings. These job postings were designed based on real job postings from our field experiment, each one correponding to one of the three job categories used in the field experiment (i.e., Administrative/Clerical, Sales, Customer Service). We created six candidate resumes for each of the three possible job postings, and the two resumes presented to the respondent are chosen randomly from the appropriate set of six (and ordered randomly on the web page). These resumes were designed based on the fictitious resumes actually used in our field experiment. After being presented with the job posting and the two resumes, the respondent was then asked to select one of the two resumes to contact for an in-person job interview.

In the second stage (Appendix Figure A2), the respondent was required to perform two tasks. First, she was asked to recall specific information on each of the two resumes, such as total work experience, tenure at last job, level of education, current employment status, and the length of unemployment spell. ${ }^{43}$ Importantly, the respondent was precluded from viewing the resumes after making her selection. If the respondent attempted to click the "Back" button on her browser, she was warned that this would invalidate her survey response. Second, the respondent was asked to indicate which two resume attributes were most important in evaluating the job applicant's resume, and to rank these two attributes by importance. ${ }^{44}$ In the third stage of the survey (Appendix Figure A3), the respondent is asked several demographic questions.

\footnotetext{
${ }^{40}$ We refer the reader to Blanchard and Diamond who show more directly that $h(d)=a \exp \left(-a \frac{U(d)}{V}\right)$ is decreasing in labor market tightness, $\frac{U}{V}$.

${ }^{41}$ There were 91 students who completed the survey, but one of the responses contained missing responses for most of the requested information and so was dropped from the analysis.

${ }^{42} \mathrm{We}$ measure time-to-completion by treating the IP address of the respondent as a unique identifier.

${ }^{43}$ The ordering of these questions was chosen at random for each respondent.

${ }^{44}$ The ordering of these attributes was chosen at random for each respondent.
} 
We use the responses to the "recall" questions in the second stage to measure the salience of the various resume characteristics. The results are reported in Appendix Table A1. The full sample used to measure salience comprises all of the resumes evaluated by all of the respondents, which is $N=180$, since each of the 90 respondents had to recall information for two resumes.

In Panel A of Appendix Table A1, we report results which compute how often the respondent correctly recalled the information, and we repeat this for each resume characteristic. The first row shows that respondents were able to correctly recall the level of education on the resume $65 \%$ of the time. This is similar to $66 \%$ of the time that the respondents were able to correctly recall whether or not the job applicant was currently employed. The respondents were particularly likely to recall the number of jobs that the applicant held; this information is correctly recalled $85 \%$ of the time. The last three rows of Panel A report results for the length of the unemployment spell, total work experience, and tenure at previous job, respectively. For these cases, we define the respondent as correctly recalling the information if the response is within a given window around the "actual" value, where the window varies by characteristic (and roughly scales with the average value of the characteristic across the resumes used in the survey). ${ }^{45}$ Using this definition, respondents correctly recall length of unemployment spell $52 \%$ of the time, total work experience $64 \%$ of the time, and tenure at previous job $47 \%$ of the time. The second column of Panel A reports analgous results for the subsample of respondents who report "high experience" in reviewing resumes (corresponding to a 4 or a 5 on a 5 -point scale, which comprises roughly $19 \%$ of the full sample). The results are broadly similar for this subsample, with more respondents in this subsample correctly recalling the length of unemployment spell and whether job applicant was currently employed.

Next, in Panel B we report an alternative measure of salience: the correlation between the "recalled" information and the "actual" resume characteristic. This correlation is based on the variation across resumes in the values of these characteristics. Across all of the rows in the table, the two values are strongly and significantly correlated, suggesting that the respondents were able to recall information. Additionally, the correlations are generally higher among the subsample of respondents with "high experience". Consistent with the results in Panel A, the correlation for length of unemployment spell is similar in magnitude to the correlations for the other variables. We also report the "mean \% error" (defined as the average percentage difference between the "recalled" and "actual" values across all survey responses). This number is similar across characteristics, confirming that the respondents are not substantially biased on average in recalling specific information. We interpret the results in Panel A and Panel B as being broadly consistent with students being aware of employment status and length of unemployment spell, in addition to the other resume characteristics that they were asked to recall.

Lastly, in Panel $\mathrm{C}$ we report results from the subjective survey question which asked respondents to list the two most important attributes in evaluating the job applicant's resume. Interestingly, there is overwhelming preference for the resumes to have "relevant work experience", with very few respondents indicating employment status or length of unemployment spell as being one of the two most important attributes. $^{46}$ These results may shed light on why resume audit studies typically explain so little variation in callback rates: if employers are primarily trying to gauge whether the work experience is specifically relevant for the job, and this information is not being measured or manipulated by researchers, then the ability of the other covariates to explain variation in callback rates will be limited.

Overall, the results of this survey are consistent with our assumption that employers in our experiment

\footnotetext{
${ }^{45}$ The resumes in the survey have 84 months of work experience on average (std. dev. 18 months). For job tenure, the mean is 51 months (std. dev. 20 months). Finally, for length of unemployment spell, the mean (conditional on not being currently employed) is 20 months (std. dev. 9 months). The unemployment spells are chosen from set $\{8,14,20,27,36\}$. One reason why we choose the 4-month window for the length of unemployment spell is that there is a clear mass of respondents who respond with 12 and 24 months when true value of unemployment spell is 8 and 20, respectively. More than half of the survey respondents only provide year (and no month) for experience, job tenure, and unemployment spell. This could be consistent with a memory-based "heuristic" that rounds to the nearest year, or alternatively the respondents wanted to complete the survey more quickly and did not bother to guess the exact month for these characteristics.

${ }^{46}$ In pilot survey, we did not have "relevant work experience", and every student taking pilot survey responded that this would have been their first choice.
} 
are aware of the employment status and the length of the unemployment spell, at least to the extent that they are aware of other information on the resume, such level of education, total work experience, and tenure at last job. While there is an important caveat that the survey respondents are not a representative sample of the individuals evaluating resumes in our field experiment, we are reassured that our results persist in the subsample of MBA students with high levels of experience actually reviewing resumes.

\section{Appendix G: Covariance Between City Fixed Effects and City-Specific Effect of Unemployment Duration}

Recall the following estimating equation from the main text:

$$
y_{i, c}=\alpha_{1} E_{i, c}+\delta^{c}+\gamma^{c} \log \left(d_{i, c}\right)+X_{i, c} \Gamma+\varepsilon_{i, c}
$$

where $\delta^{c}$ is a metropolitan area fixed effect and $\gamma^{c}$ is a MSA-specific estimate of the effect of unemployment duration. We test for whether duration dependence varies with labor market conditions by treating $\delta^{c}$ as a proxy measure of labor market tightness and then estimating the covariance between $\delta^{c}$ and $\gamma^{c}$; i.e. $E\left[\left(\delta^{c}-\bar{\delta}^{c}\right) \gamma^{c}\right]$. We compute this by first computing the covariance between the estimates; i.e., $E\left[\hat{\delta}^{c} \hat{\gamma}^{c}\right]$. Defining $\hat{\eta}_{\delta}^{c}$ as estimation error for $\hat{\delta}^{c}$ (i.e., $\hat{\delta}^{c}=\delta^{c}+\hat{\eta}_{\delta}^{c}$ ) and $\hat{\eta}_{\gamma}^{c}$ as estimation error for $\hat{\gamma}^{c}$, then we can compute $E\left[\hat{\delta}^{c} \hat{\gamma}^{c}\right]$ as follows:

$$
\begin{aligned}
E\left[\hat{\delta}^{c} \hat{\gamma}^{c}\right] & =\frac{1}{C} \sum_{c=1}^{C} \hat{\delta}^{c} \hat{\gamma}^{c} \\
& =\frac{1}{C} \sum_{c=1}^{C}\left(\delta^{c}+\hat{\eta}_{\delta}^{c}\right)\left(\gamma^{c}+\hat{\eta}_{\gamma}^{c}\right) \\
& =\frac{1}{C} \sum_{c=1}^{C} \delta^{c} \gamma^{c}+\frac{1}{C} \sum_{c=1}^{C} \delta^{c} \hat{\eta}_{\gamma}^{c}+\frac{1}{C} \sum_{c=1}^{C} \hat{\eta}_{\delta}^{c} \gamma^{c}+\frac{1}{C} \sum_{c=1}^{C} \hat{\eta}_{\delta}^{c} \hat{\eta}_{\gamma}^{c}
\end{aligned}
$$

where $C$ is the total number of cities in the sample. We can re-write this using expectations as follows (using the fact that $E_{c}\left[\hat{\eta}_{\gamma}^{c}\right]=0$ and $E_{c}\left[\hat{\eta}_{\delta}^{c}\right]=0$ ):

$$
E\left[\hat{\delta}^{c} \hat{\gamma}^{c}\right]=E\left[\delta^{c} \gamma^{c}\right]+\frac{1}{C} \sum_{c=1}^{C} E_{c}\left[\hat{\eta}_{\delta}^{c} \hat{\eta}_{\gamma}^{c}\right]
$$

Next, we can compute $E_{c}\left[\hat{\eta}_{\delta}^{c} \hat{\eta}_{\gamma}^{c}\right]$ using standard statistical results:

$$
E_{c}\left[\hat{\eta}_{\delta}^{c} \hat{\eta}_{\gamma}^{c}\right]=-\frac{\sigma_{c}^{2}}{N^{c}} \frac{E_{c}[\log (d)]}{\operatorname{Var}(\log (d))}
$$

where $\sigma_{c}^{2}$ is the residual variance for MSA $c$, and $N^{c}$ is the number of observations in the MSA. Combining the above gives us the following expression for the unbiased estimate of $E\left[\delta^{c} \gamma_{2}^{c}\right]$ :

$$
E\left[\left(\delta^{c}-\bar{\delta}^{c}\right) \gamma^{c}\right]=\frac{1}{C} \sum_{c=1}^{C} \hat{\delta}^{c} \hat{\gamma}^{c}+\frac{1}{C} \sum_{c=1}^{C} \frac{\hat{\sigma}_{c}^{2}}{N^{c}} \frac{E_{c}[\log (d)]}{\operatorname{Var}(\log (d))}
$$

In other words, there is a negative bias in estimated covariance if one simply computes empirical covariance based on the regression estimates $\hat{\delta}^{c}$ and $\hat{\gamma}^{c}$. Intuitively, this bias comes from the fact that the sampling errors in the estimates for these two parameters for a given MSA are negatively correlated. While this bias goes away asymptotically, it requires both that $C \rightarrow \infty$ and $N^{C} \rightarrow \infty$. In Monte Carlo simulations 
resembling our experimental data, we find substantial bias unless we use the bias correction above.

We conduct inference on the estimated covariance by computing the following standard error estimate, and we have verified that these standard errors are reliable using Monte Carlo simulations:

$$
s e\left(\widehat{E\left[\delta^{c} \gamma^{c}\right]}\right)=\sqrt{\frac{1}{C}\left(\frac{1}{C} \sum_{c=1}^{C}\left(\hat{\delta}^{c}\right)^{2}\left(\hat{\gamma}^{c}\right)^{2}\right)}
$$

\section{Appendix H: Data Sources}

This section describes the various MSA-level data used in the empirical analysis:

Vacancy Data: We purchased vacancy data from Wanted Analytics (WA), which is part of Wanted Technologies. WA collects hiring demand data and is the exclusive data provider for The Conference Board's "Help-Wanted OnLine Data Series", which is a monthly economic indicator of hiring demand in the US. WA gathers its data from the universe of online vacancies posted on internet job boards or online newspapers. In total, it covers roughly 1,200 online job boards, although the vast majority of the ads appear on a small number of major job boards. When the same job ad appears on multiple job boards, WA uses a deduplication procedure to identify unique job ads on the basis of company name, job title and description and MSA or State. Sahin et al (2011) document potential measurement issues related to these data: first, the dataset records a single vacancy per ad, although it is possible that multiple positions are listed in a single ad; second, it is possible that multiple locations within a state are listed in a single ad for a given position. The data we received contains the total number of job postings by MSA, 6-digit occupation code, and year. Our sample spans 2008 through 2012.

MSA Unemployment Data: Source: United States Bureau of Labor Statistics. Link: http://data. bls.gov/cgi-bin/dsrv?la. Description: Monthly data on number of unemployed persons, number of persons in the labor force, the number of employed persons and the unemployment rate in the given MSA.

GDP in 2010: Source: US Department of Commerce, Bureau of Economic Analysis. Link: http:// www . bea.gov/newsreleases/regional/gdp_metro/gdp_metro_newsrelease.htm for original press release. Now can be reproduced at http://www.bea.gov/itable. Description: Real US GDP by metropolitan area. This is advanced GDP data, and was released in September 2011. The numbers used are chained 2005 dollars.

Median Income in 2011: Source: Federal Financial Institutions Examination Council, posting data from the Department of Housing and Urban Development. Link: http://www.ffiec.gov/cra/censusproducts . htm \\#MSAincome. Description: Median Income in 2011 for MSAs in real dollars.

Metropolitan Population Density, Median Age, Share of Population (25 Years and Above) with Bachelor's Degree, Share of Civilian Employed Population in Information Industries, Fraction of Population Non-White: Source: 2010 Census. Link: http://www. census.gov/compendia/ statab/2011/tables/11s0023.pdf 


\begin{tabular}{|c|c|c|c|c|}
\hline & \multicolumn{2}{|c|}{$\begin{array}{c}\text { All resumes } \\
(\mathrm{N}=180)\end{array}$} & \multicolumn{2}{|c|}{$\begin{array}{l}\text { Only resumes reviewed by } \\
\text { "High experience" students } \\
(\mathrm{N}=34) \\
\end{array}$} \\
\hline \multicolumn{5}{|c|}{ PANEL A: DESCRIPTIVE STATISTICS FROM SURVEY } \\
\hline & \multicolumn{2}{|c|}{ \% answering correctly } & \multicolumn{2}{|c|}{ \% answering correctly } \\
\hline $\begin{array}{l}\text { What is the level of education of the applicant? } \\
\text { [Bachelors, Associate Degree, GED, High School Grad] }\end{array}$ & \multicolumn{2}{|c|}{$65 \%$ correct } & \multicolumn{2}{|c|}{$65 \%$ correct } \\
\hline Is the job applicant currently employed? & \multicolumn{2}{|c|}{$66 \%$ correct } & \multicolumn{2}{|c|}{$82 \%$ correct } \\
\hline How many jobs has the applicant held? & \multicolumn{2}{|c|}{$85 \%$ correct } & \multicolumn{2}{|c|}{$86 \%$ correct } \\
\hline $\begin{array}{l}\text { How long is the applicant currently unemployed? } \\
\text { [Sample limited to not currently employed] }\end{array}$ & \multicolumn{2}{|c|}{$\begin{array}{l}52 \% \text { correct } \\
\text { (within } 4 \text { months) }\end{array}$} & \multicolumn{2}{|c|}{$\begin{array}{l}74 \% \text { correct } \\
\text { (within } 4 \text { months) }\end{array}$} \\
\hline What is the applicant's total work experience? & \multicolumn{2}{|c|}{$\begin{array}{l}64 \% \text { correct } \\
\text { (within } 24 \text { months) }\end{array}$} & \multicolumn{2}{|c|}{$\begin{array}{l}71 \% \text { correct } \\
\text { (within } 24 \text { months) }\end{array}$} \\
\hline How long did the applicant hold his/her last job? & \multicolumn{2}{|c|}{$\begin{array}{l}47 \% \text { correct } \\
\text { (within } 12 \text { months) }\end{array}$} & \multicolumn{2}{|c|}{$\begin{array}{l}50 \% \text { correct } \\
\text { (within } 12 \text { months) }\end{array}$} \\
\hline \multicolumn{5}{|c|}{$\begin{array}{l}\text { PANEL B: CORRELATION AND MEAN \% ERROR } \\
\text { COMPARING "RECALLED" AND "ACTUAL" RESUME CHARACTERISTICS }\end{array}$} \\
\hline & Correlation & Mean \% error & Correlation & Mean \% error \\
\hline How many jobs has the applicant held? & $\begin{array}{c}0.710 \\
(0.054)\end{array}$ & $\begin{array}{c}3.4 \% \\
(1.5 \%)\end{array}$ & $\begin{array}{c}0.647 \\
(0.135)\end{array}$ & $\begin{array}{c}5.9 \% \\
(3.8 \%)\end{array}$ \\
\hline $\begin{array}{l}\text { How long is the applicant currently unemployed? } \\
\text { [Sample limited to not currently employed] }\end{array}$ & $\begin{array}{c}0.499 \\
(0.067)\end{array}$ & $\begin{array}{l}-13.3 \% \\
(6.0 \%)\end{array}$ & $\begin{array}{c}0.757 \\
(0.115)\end{array}$ & $\begin{array}{l}-14.3 \% \\
(7.5 \%)\end{array}$ \\
\hline What is the applicant's total work experience? & $\begin{array}{c}0.419 \\
(0.070)\end{array}$ & $\begin{array}{l}-13.0 \% \\
(2.3 \%)\end{array}$ & $\begin{array}{c}0.664 \\
(0.132)\end{array}$ & $\begin{array}{l}-11.4 \% \\
(3.8 \%)\end{array}$ \\
\hline How long did the applicant hold his/her last job? & $\begin{array}{c}0.447 \\
(0.069)\end{array}$ & $\begin{array}{l}-11.1 \% \\
(5.2 \%)\end{array}$ & $\begin{array}{c}0.771 \\
(0.113)\end{array}$ & $\begin{array}{l}-9.7 \% \\
(9.3 \%)\end{array}$ \\
\hline
\end{tabular}

\section{PANEL C: RANKING RESUME ATTRIBUTES BY IMPORTANCE}

Which two attributes were most important in evaluating the job applicant's resume?

\begin{tabular}{lcccc} 
& $1^{\text {st }}$ choice & $2^{\text {nd }}$ choice & $1^{\text {st }}$ choice & $2^{\text {nd }}$ choice \\
\hline Years of work experience & $4 \%$ & $29 \%$ & $11 \%$ & $28 \%$ \\
Length of time at most recent job & $0 \%$ & $13 \%$ & $0 \%$ & $17 \%$ \\
Level of education & $9 \%$ & $28 \%$ & $11 \%$ & $39 \%$ \\
Number of jobs held by applicant & $0 \%$ & $12 \%$ & $0 \%$ & $0 \%$ \\
Relevant work experience & $84 \%$ & $8 \%$ & $74 \%$ & $6 \%$ \\
Current employment status & $1 \%$ & $2 \%$ & $0 \%$ & $0 \%$ \\
Length of time out of work & $2 \%$ & $7 \%$ & $5 \%$ & $11 \%$ \\
\hline \hline
\end{tabular}

Notes: This table reports results from a web-based survey administered to first-year MBA students at the University of Chicago Booth School of Business. Details of the survey are given in the Appendix. The table reports results for entire sample as well as a subsample of survey respondents who reported high experience in reviewing resumes (either a 4 or 5 on a 5-point scale). Standard errors are reported in parentheses in Panel B. 
Appendix Table A2

The Effect of Unemployment Duration on

Probability of Callback

\begin{tabular}{|c|c|c|}
\hline \multicolumn{3}{|c|}{ Dependent variable: Received callback for interview } \\
\hline & (1) & $(2)$ \\
\hline \multirow[t]{3}{*}{ log(Months unemployed) } & -0.011 & -0.012 \\
\hline & $(0.003)$ & $(0.003)$ \\
\hline & {$[0.000]$} & {$[0.000]$} \\
\hline \multirow[t]{3}{*}{$\mathbf{1}\{$ Employed $\}$} & -0.020 & -0.023 \\
\hline & $(0.010)$ & $(0.010)$ \\
\hline & {$[0.040]$} & [0.019] \\
\hline \multirow[t]{3}{*}{ Unemployment rate } & & -0.003 \\
\hline & & $(0.001)$ \\
\hline & & [0.007] \\
\hline \multirow[t]{3}{*}{ Some college } & -0.014 & -0.016 \\
\hline & $(0.006)$ & $(0.006)$ \\
\hline & [0.017] & [0.006] \\
\hline \multirow[t]{3}{*}{ College degree } & -0.014 & -0.018 \\
\hline & $(0.008)$ & $(0.008)$ \\
\hline & [0.065] & [0.022] \\
\hline \multirow[t]{3}{*}{ High quality } & 0.011 & 0.012 \\
\hline & $(0.004)$ & $(0.004)$ \\
\hline & {$[0.010]$} & [0.005] \\
\hline \multirow[t]{3}{*}{ Female } & 0.002 & 0.003 \\
\hline & $(0.004)$ & $(0.004)$ \\
\hline & [0.529] & [0.502] \\
\hline \multirow[t]{3}{*}{ Customer service job } & 0.029 & 0.029 \\
\hline & $(0.006)$ & $(0.006)$ \\
\hline & {$[0.000]$} & {$[0.000]$} \\
\hline \multirow[t]{3}{*}{ Sales job } & 0.057 & 0.057 \\
\hline & $(0.007)$ & $(0.007)$ \\
\hline & {$[0.000]$} & {$[0.000]$} \\
\hline Average callback rate in estimation sample & 0.047 & 0.047 \\
\hline $\mathrm{N}$ & 12054 & 12054 \\
\hline $\mathrm{R}^{2}$ & 0.038 & 0.016 \\
\hline MSA fixed effects & $\mathrm{X}$ & \\
\hline Baseline controls & $\mathrm{X}$ & $X$ \\
\hline
\end{tabular}

Notes: All columns report OLS linear probability model estimates. Data are resume-level submissions matched to callbacks from employers to request an interview. Standard errors, adjusted to allow for an arbitrary variance-

covariance matrix for each employment advertisement, are in parentheses and pvalues are in brackets. 
Appendix Table 3

How Does Duration Dependence Vary With Labor Market Conditions?

[Linear Probability Model Alternatives]

\begin{tabular}{|c|c|c|c|c|c|}
\hline \multicolumn{6}{|c|}{ Dependent variable: Received callback for interview } \\
\hline & \multicolumn{5}{|c|}{$\begin{array}{c}\text { Interaction term formed using proxy for } \\
\text { local labor market conditions, } \boldsymbol{X}=\ldots\end{array}$} \\
\hline & \multicolumn{3}{|c|}{$u_{2011^{-}}$} & \multirow{3}{*}{$\begin{array}{c}-V / U \\
(4)\end{array}$} & \multirow{3}{*}{$\begin{array}{c}-\log (V / U) \\
(5)\end{array}$} \\
\hline & $u$ & $u_{2008}$ & $\log (u)$ & & \\
\hline & (1) & $(2)$ & (3) & & \\
\hline \multicolumn{6}{|c|}{ Panel A: Results from Probit Regressions } \\
\hline \multirow[t]{3}{*}{$\log$ (Months unemployed) } & -0.009 & -0.009 & -0.009 & -0.009 & -0.009 \\
\hline & $(0.002)$ & $(0.002)$ & $(0.002)$ & $(0.002)$ & $(0.002)$ \\
\hline & {$[0.000]$} & {$[0.000]$} & {$[0.000]$} & {$[0.000]$} & {$[0.000]$} \\
\hline \multirow[t]{3}{*}{$\log ($ Months unemployed $) \times \boldsymbol{X}$} & 0.135 & 0.269 & 0.014 & 0.002 & 0.007 \\
\hline & $(0.061)$ & $(0.111)$ & $(0.005)$ & $(0.001)$ & $(0.003)$ \\
\hline & {$[0.028]$} & [0.015] & {$[0.007]$} & {$[0.003]$} & [0.031] \\
\hline \multirow[t]{3}{*}{$\boldsymbol{X} \quad$ [Proxy for local labor market conditions $]$} & -0.282 & -0.478 & -0.029 & -0.004 & -0.016 \\
\hline & $(0.107)$ & $(0.198)$ & $(0.010)$ & $(0.002)$ & $(0.006)$ \\
\hline & [0.009] & {$[0.016]$} & [0.004] & [0.004] & [0.006] \\
\hline Standardized effect of interaction term & 0.0034 & 0.0034 & 0.0037 & 0.0037 & 0.0031 \\
\hline Standardized effect of $X$ & -0.0070 & -0.0061 & -0.0074 & -0.0068 & -0.0069 \\
\hline $\mathrm{N}$ & 12054 & 12054 & 12054 & 12054 & 12054 \\
\hline \multicolumn{6}{|c|}{ Panel B: Results from Fixed-Effects Poisson Regressions } \\
\hline \multirow[t]{3}{*}{$\log ($ Months unemployed) } & -0.215 & -0.216 & -0.212 & -0.213 & -0.217 \\
\hline & $(0.052)$ & $(0.052)$ & $(0.052)$ & $(0.052)$ & $(0.052)$ \\
\hline & {$[0.000]$} & {$[0.000]$} & {$[0.000]$} & {$[0.000]$} & {$[0.000]$} \\
\hline \multirow[t]{3}{*}{$\log ($ Months unemployed $) \times \boldsymbol{X}$} & 2.615 & 5.891 & 0.286 & 0.048 & 0.135 \\
\hline & (1.300) & (2.605) & (0.119) & $(0.019)$ & $(0.073)$ \\
\hline & [0.044] & [0.024] & [0.016] & [0.011] & [0.064] \\
\hline Standardized effect of interaction term & 0.0665 & 0.0766 & 0.0756 & 0.0769 & 0.0595 \\
\hline $\mathrm{N}$ & 11229 & 11229 & 11229 & 11229 & 11229 \\
\hline
\end{tabular}

Notes: All columns report models analogous to Panel A in Table 7 replacing the linear probability model with a probit model and a fixed-effects Poisson model. Data are resume-level submissions matched to callbacks from employers to request an interview. The controls included are the following: indicator variables for Associate degree, Bachelor's Degree, High quality resume, Female gender, and three job categories. In Panel B, MSA fixed effects are also included as controls and the sample size is reduced because MSAs without any callbacks are dropped. Standard errors, adjusted to allow for an arbitrary variance-covariance matrix for each employment advertisement, are in parentheses and p-values are in brackets. 


\section{Appendix Figure A1}

\section{GHIGIGOBOOHI}

\section{Chicago Booth Web-Based Resume Survey}

\section{Survey Instructions}

We would like you to put yourself in the hypothetical situation of a Human Resource Manager who is currently trying to fill an opening for a job as a Customer Service Representative. Yov are considering two resumes that were submitted earlier today.

Please spend a few minutes reading the job description and the two resumes below, and then evaluate (in your capacity as the HR Manager) which of the two applicants you would contact to set up an in-person interview for the job.

Once you have finished evaluating the resume, you will then be asked several questions about the job applicant on the next page.

\section{Job Description}

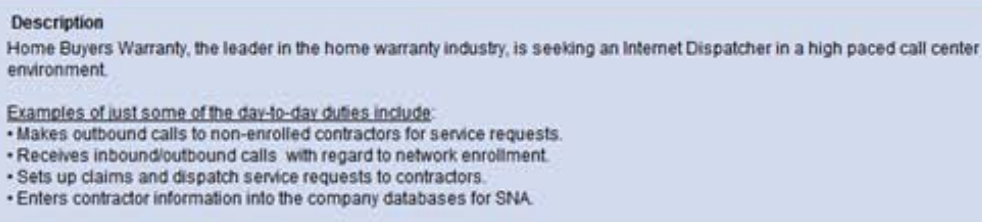

\section{Resume \#1: Jennifer Moore}

\section{Jennifer Moore}

\section{OQUECTIVE}

Seeking a position with a reputable organization where I can uttilte my experience in customer service. SUMMARY OF QUAUACATLONS

lam a very motvased, responsible, and ambetious indvidual. I enjoynew chalenges and value working with others. 1 am locking for an organieation that values its excellense, while peovidng a workplace the seeks to bothteachand learn fromas semplopees.

toucanow

Aprahoe Ridge High school Goulder, Co - G.E.D.

EXeraience

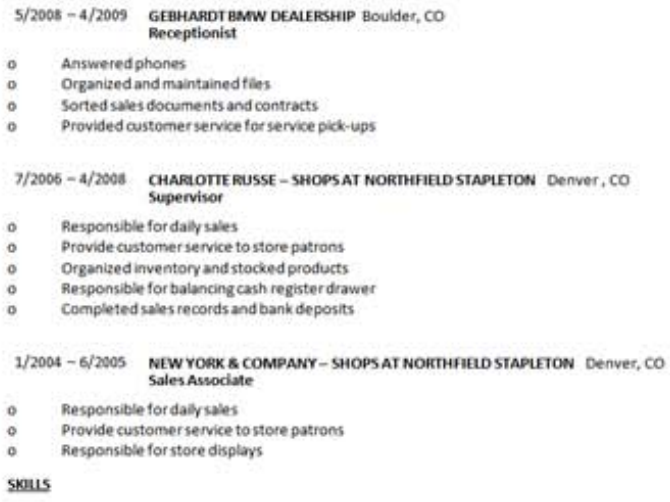

Please select which applicant should be contacted for an interview

$$
\text { Resume \#1: Jennifer Moore }
$$

\section{Resume \#2: Timothy Collins}

TIMOTHY COLLINS

982 Rowena Street, Thomton, Adams, Colorado 80229

timothrcollins.8101@yahoo.com

\section{SUMMARY}

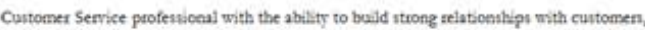
cowoaken and potential clients. Ptofensional and handwoeking individual deroted to improring compant's reputation through exreptional customer service

PROFESSIONAL EXPERIENCE

Target

Customer Service Managet

Limleton, Colorado

Mas 2006 - August 2010

- Recommended, selected, and helped locate metchandire based on cuntomer need. and derise:

- Revolied costo

- Reiolied casto
necenary.

- Enomed

- Examined metchandise to ensare that ir is coneetly proed asd displared

Conducted matket reseatch, identified emering urends, and introduced marketing

- Operated call regites, handled money and pettormed daily check out procedart:

Tebo Stoee Fixtares

Denvet, Colorado Custorner Service Repece

- Trained new hitel in a vasety of watebouse department

- Made vare itema wete in good lhape and that packaper wete teceired and hipped timei).

- Condueted and epperted moethly iarentory of watthosse itema

- Pronided office support and adminittatire antitance for customer onders peocening and computer tracking

\section{EDUCATION}

Westrood College - Denver North Campus Denver, Colorado 


\section{Appendix Figure A2}

\section{GH:B:BOBOOHL}

\section{Chicago Booth Web-Based Resume Survey}

\section{Resume Characteristics}

For all of the questions below, you should provide your BEST GUESS if you are not able to remember something exactly.

You should NOT click the BACK button; doing so will invalidate your survey response.

Q1: How many jobs has the applicant held? (Please provide your BEST GUESS)

[NOTE: Including the current job, if applicable]

Q2: How long is the applicant currently unemployed? (Please provide your BEST GUESS)

[NOTE: If the applicant is currently employed, please select "0"]

Q3: What is the applicant's total work experience? (Please provide your BEST GUESS)

[NOTE: Include years at current job, if applicable]

Q4: What is the level of education of the applicant? (Please provide your BEST GUESS)

Q5: How long did the applicant hold his her last job? (Please provide your BEST GUESS)

[NOTE: Use months at current job, if applicable]

Q6: Is the job applicant currently employed? (Please provide your BEST GUESS)

\section{Resume \#1: Jennifer Moore}

- Jobs

- Years, $\rightarrow$ Months

- Years, Months

High School Degree 9 GED

Associate Degree Bachelors Degree

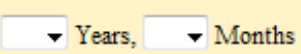

$\checkmark$ Yes No

\section{Resume \#2: Timothy Collins}

- Jobs

- Years, - Months

- Years, $\rightarrow$ Months

High School Degree GED

Associate Degree Bachelors Degree

$$
\text { - Years, - Months }
$$

Yes No

\section{Ranking Attributes}

Among the list of attributes below, please select the two that were the most important in evaluating the job applicant's resume.

Please place a "1" to indicate the most important attribute and a "2" to indicate the second-most important attribute.

Current employment status

Number of jobs held by applicant

Years of work experience

Length of time out of work

Level of education

Relevant work experience

Length of time at most recent job 


\section{Appendix Figure A3}

\section{GHICHEOBOOHE}

The Univarsity of Ehitago Bonth Sehoul of Business

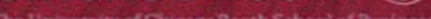

\section{Chicago Booth Web-Based Resume Survey}

\section{Wrap-Up Questions}

To complete the survey, please answer the following background questions.

Please indicate your overall level of experience in reviewing resumes for recruiting new hires, interns, etc.?
(no experience) $\bigcirc 1$
$\bigcirc 2 \bigcirc 3 \bigcirc 4$
5 (very experienced)

Have you worked in Human Resources before?

$\odot$ Yes No

What is your gender?

Male Female 
Figure A4: City Fixed Effect vs. Unemployment Rate

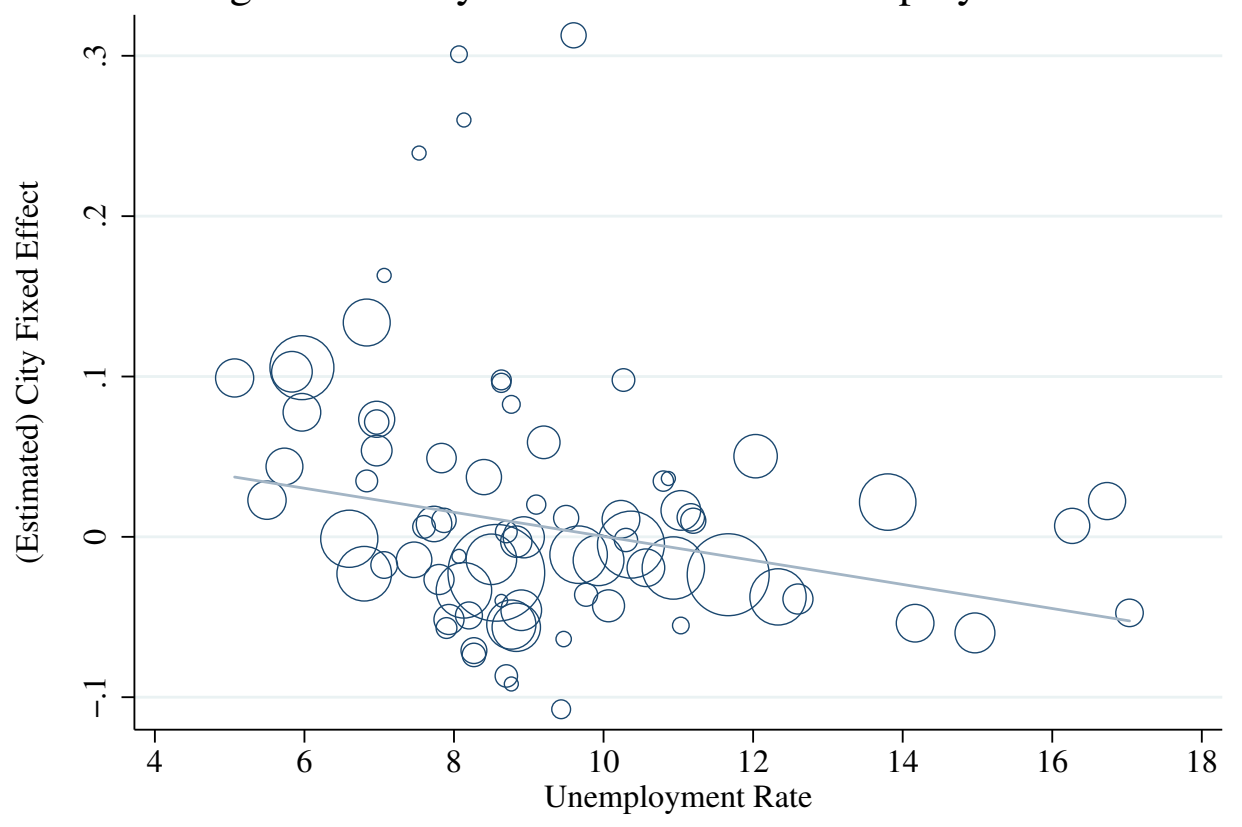

Figure A5: City Fixed Effect vs. V-U Ratio

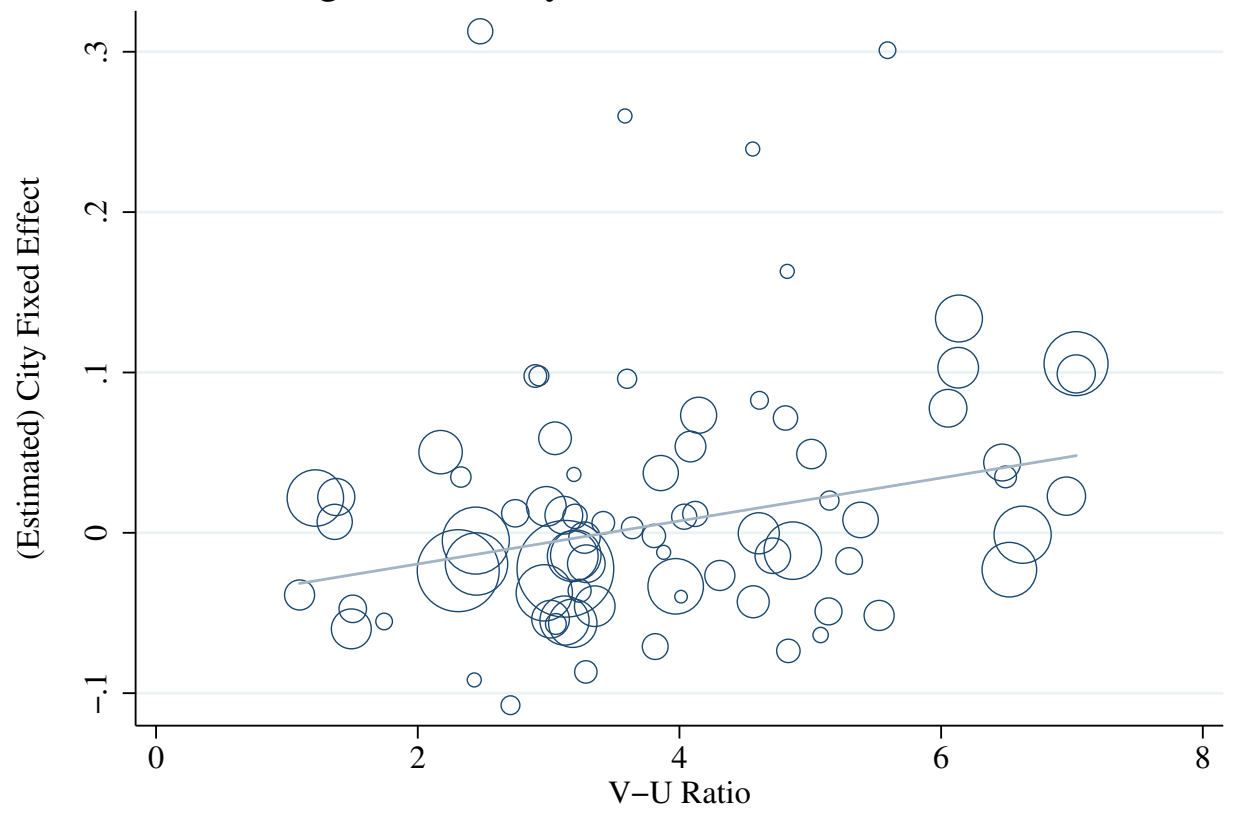

Notes: These figures show the correlation between the estimated city-specific fixed effects and two alternative proxies for market tightness. The solid line is the weighted OLS regression line using the number of observations in the city for the weights. The size of the circles are proportional to these weights. 